\title{
Defining species boundaries in the Merodon avidus complex (Diptera, Syrphidae) using integrative taxonomy, with the description of a new species
}

\author{
Jelena AČANSKI ${ }^{1, *}$, Ante VUJIĆ ${ }^{2}$, Mihajla DJAN ${ }^{3,7}$, Dragana OBREHT VIDAKOVIĆ ${ }^{4,7}$, \\ Gunilla STÅHLS ${ }^{5}$ \& Snežana RADENKOVIĆ ${ }^{6,7}$ \\ ${ }^{1}$ University of Novi Sad, BioSense Institute - Research Institute for Information Technologies in \\ Biosystems, Trg Dr Zorana Đinđića 1, 21000 Novi Sad, Serbia. \\ ${ }^{2,7}$ Department of Biology and Ecology, Faculty of Sciences, University of Novi Sad, \\ Trg Dositeja Obradovića 2, 21000 Novi Sad, Serbia. \\ ${ }^{5}$ Zoology Unit, Finnish Museum of Natural History, PO Box 17, 00014 University of Helsinki, Finland. \\ "Corresponding author: acanskijelena@gmail.com \\ ${ }^{2}$ Email: ante.vujic@dbe.uns.ac.rs \\ ${ }^{3}$ Email: mihajla.djan@dbe.uns.ac.rs \\ ${ }^{4}$ Email: dragana.obreht@dbe.uns.ac.rs \\ ${ }^{5}$ Email: gunilla.stahls@,helsinki.fi \\ ${ }^{6}$ Email: snezana.radenkovic@,dbe.uns.ac.rs

\footnotetext{
${ }^{1}$ urn:lsid:zoobank.org:author:F02841B0-AC6B-4FC4-A64A-D13A3355B079

${ }^{2}$ urn:lsid:zoobank.org:author:A20D5863-CF18-4BF7-BB68-0DA75D34B7A8

${ }^{3}$ urn:lsid:zoobank.org:author:BE29D9A9-CC69-416C-8F85-4B8AA99A6C71

${ }^{4}$ urn:lsid:zoobank.org:author:75E52F0E-EEDC-4EF1-907B-9202DBDEAC9F

${ }^{5}$ urn:Isid:zoobank.org:author:D19B1262-503A-48E2-91AE-F99D0F2EA3A3

${ }^{6}$ urn:1sid:zoobank.org:author:26DF35D9-55FA-4485-8E8C-C1F90EFE1036
}

\begin{abstract}
Several recent studies have detected and described complexes of cryptic and sibling species in the genus Merodon (Diptera, Syrphidae). One representative of these complexes is the Merodon avidus complex that contains four sibling species, which have proven difficult to distinguish using traditional morphological characters. In the present study, we use two geometric morphometric approaches, as well as molecular characters of the 5'-end of the mtDNA COI gene, to delimit sibling taxa. Analyses based on these data were used to strengthen species boundaries within the complex, and to validate the status of a previously-recognized cryptic taxon from Lesvos Island (Greece), here described as Merodon megavidus Vujić \& Radenković sp. nov. Geometric morphometric results of both wing and surstylus shape confirm the present classification for three sibling species - M. avidus (Rossi, 1790), M. moenium Wiedemann in Meigen, 1822 and M. ibericus Vujić, 2015 - and, importantly, clearly discriminate the newly-described taxon Merodon megavidus sp. nov. In addition to our geometric morphometric results, supporting characters were obtained from molecular analyses of mtDNA COI sequences, which clearly differentiated M. megavidus sp. nov. from the other members of the M. avidus complex. Molecular analyses revealed that the earliest divergence of $M$. ibericus occurred around $800 \mathrm{ky} \mathrm{BP}$, while the most recent separation happened between M. avidus and M. moenium around $87 \mathrm{ky} \mathrm{BP.}$
\end{abstract}


Keywords. Merodon avidus complex, COI, geometric morphometry, wing, surstylus.

Ačanski J., Vujić A., Djan M., Vidaković D.O., Ståhls G. \& Radenković S. 2016. Defining species boundaries in the Merodon avidus complex (Diptera, Syrphidae) using integrative taxonomy, with the description of a new species. European Journal of Taxonomy 237: 1-25. http://dx.doi.org/10.5852/ejt.2016.237

\section{Introduction}

The genus Merodon Meigen, 1803 (Diptera: Syrphidae: Merodontini) has become the largest European hoverfly genus due to several recent studies describing many new taxa (Marcos-García et al. 2007; Popov 2010; Radenković et al. 2011; Vujić et al. 2007, 2012, 2013a, 2013b, 2015). A considerable number (37 of 57 species in southeastern Europe) of the taxa are morphologically and/or genetically cryptic, with restricted distributional ranges in particular mountain ranges or islands (Vujić et al. 2016). Larvae of Merodon species are phytophagous on the underground storage organs of plants (Amaryllidaceae, Iridaceae and Hyacinthaceae) (Hurkmans 1993; Andrić et al. 2014). Larvae of Merodon avidus (Rossi, 1790) were recently found in the bulbs of Ornithogalum umbellatum L. (Hyacinthaceae) (Andric et al. 2014). This host plant is an important foodstuff for adults, as well as for larval development and is widespread in Europe, Southwestern Asia and North Africa. Distribution of this host plant is wider than, but overlaps with, the range of the M. avidus complex (Andrić et al. 2015; Popović et al. 2015).

Taxa of the Merodon avidus complex have been the subject of many studies in the last decade due to perceived taxonomic difficulties (Milankov et al. 2001, 2009; Ståhls et al. 2009). The M. avidus complex is characterized by a considerable morphological variability, especially in the coloration of the antennae, thorax, abdomen and legs (Popović et al. 2015). This colour variability has been explained by the differential availability of trophic resources during the larval stage (Hurkmans 1993). Popović et al. (2015) provided justifications for the identification of three species from the M. avidus complex based on new diagnostic morphological characters, records of the seasonal activity and geographical distribution of bi-voltine adults, nuclear allozyme and mtDNA COI sequence analyses, and descriptions of the ecological preferences of the taxa.

However, difficulties in distinguishing the species of this complex based on morphological characters remain, despite the numerous studies on the subject. Spring generations of Merodon avidus are very similar to those of M. moenium Wiedemann in Meigen, 1822 based on external morphology, and, so, are easily confused using existing diagnostic features (e.g., Milankov et al. 2001). Furthermore, it is important to note that species of the M. avidus complex are not distinguishable by traditional visual identification of the structures of male genitalia under a stereo microscope. Additionally, in their analysis of COI barcodes of all Merodon species from Lesvos Island (Greece), Ståhls et al. (2009) revealed the presence of one cryptic taxon (Merodon sp. nova 2, herein described as M. megavidus sp. nov.) within the M. avidus complex, but did not present morphological diagnostic characters to enable characterization of the new taxon.

In the present study, two different geometric morphometric approaches were applied to quantify wing and surstylus shape variability among all hitherto described species of the Merodon avidus complex, including the new fourth taxon M. megavidus sp. nov. Insect wing shape is highly heritable and constitutes an important character for separating species (Birdsall et al. 2000). Geometric morphometric analysis of the wing shape has been successfully used in taxonomic studies of multiple hoverfly taxa (Francuski et al. 2009; Vujić et al. 2013b; Nedeljković et al. 2013, 2015). The structure and/or shape of parts of the male genitalia are very informative and thus useful for Syrphidae taxonomy and systematics (e.g., Hippa \& Ståhls 2005). Differences in male genitalia structure (particularly the surstyli and aedeagal parts) detected in morphological taxonomic studies of hoverflies have revealed them to be an 
important mechanism of isolation between species (Rotheray \& Gilbert 2011). However, differences in genitalia structure between closely-related species can be very small, as shown for many hoverfly genera (Dušek \& Laska 1964; Hippa 1990; Nedeljković et al. 2013, 2015; Vujić et al. 2013b, 2015). Geometric morphometric analysis of surstylus shape can reveal subtle shape differences that are not detectable or quantifiable by traditional visual examination (Mutanen \& Pretorius 2007). This approach has only recently been applied to the taxonomy of the Syrphidae, having been successfully implemented in the genus Chrysotoxum Meigen, 1803 to distinguish four species (Nedeljković et al. 2013, 2015). The male genitalia of Merodon species are sclerotized and rigid and thus stable structures, so they are well suited for geometric morphometric analysis.

Our study had three objectives: (1) to further clarify the species borders of all taxa within the M. avidus complex using integrative taxonomy (geometric morphometrics of wings and male surstylus shape and mtDNA COI sequences); (2) to estimate times of divergence among investigated taxa; and (3) to provide descriptions and diagnostic characters of the new species. A typological (or morphological) species concept is applied in this study, integrating all available data.

\section{Material and methods}

\section{Studied material}

A total of 444 specimens belonging to the Merodon avidus complex from Bulgaria, Croatia, Greece, Italy, Montenegro, Morocco, Serbia, Spain and Turkey was analysed (Fig. 1; Appendix 1). Specimens of $M$. avidus were sampled during spring, summer and autumn. All specimens were identified by Ante Vujić and Snežana Radenković, and labelled using unique codes.

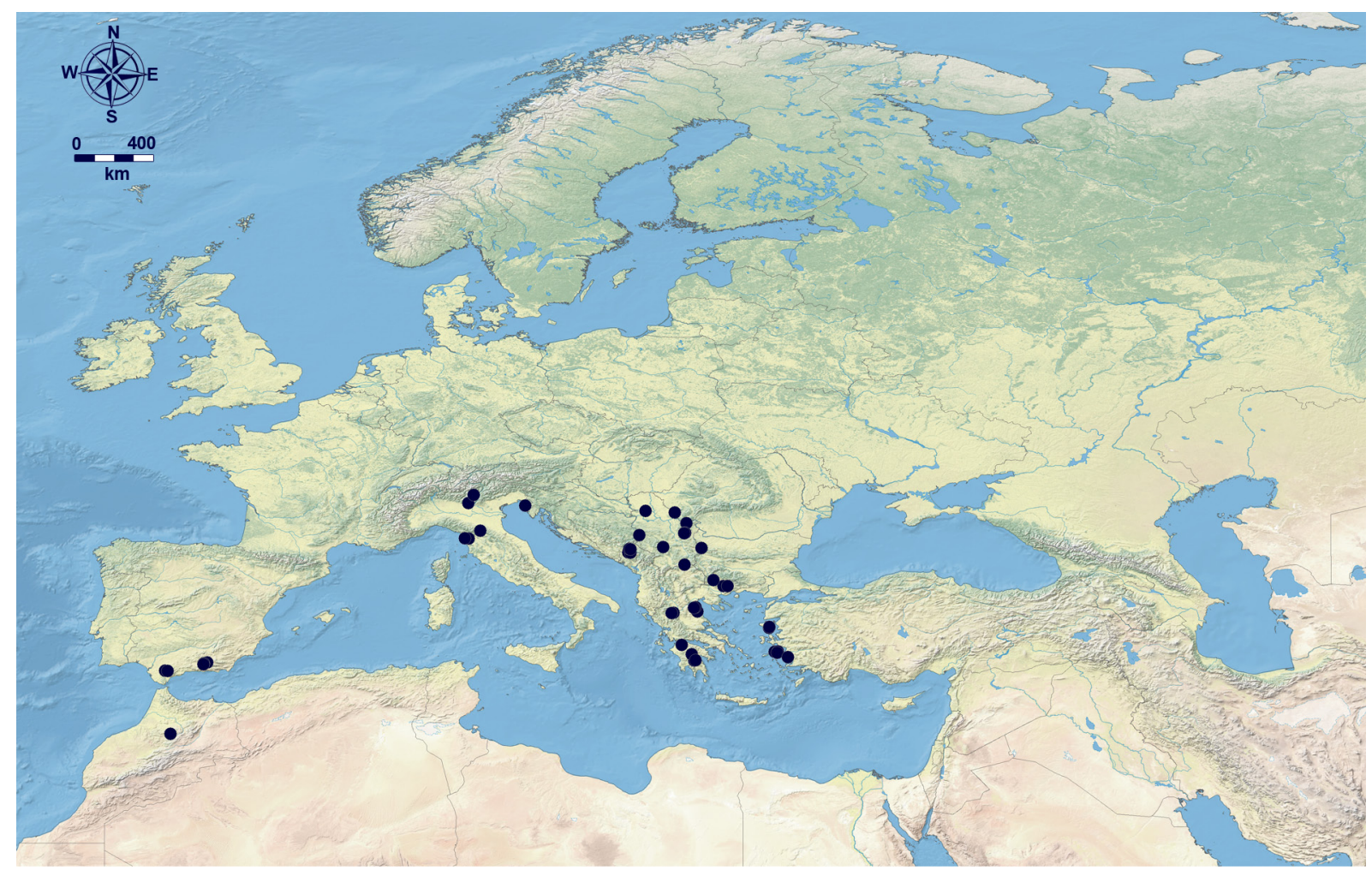

Fig. 1. Map of population sampling locations of the Merodon avidus complex from the Western Palaearctic. 
Specimens detailed in the Results are in the collections of the following institutions:

FSUNS = Department of Biology and Ecology, Faculty of Sciences, University of Novi Sad, Serbia

$\mathrm{MZF}=$ Finnish Museum of Natural History, Helsinki, Finland

$\mathrm{WML}=$ World Museum Liverpool, UK

Numbers given alongside the abbreviations FSUNS, MZH, and WML in the text refer to unique identifiers from the specimen database stored in the internal electronic database of the Faculty of Sciences, University of Novi Sad.

For the description of the new species, the terminology follows McAlpine (1981) for non-genitalic morphology and Marcos-García et al. (2007) for morphology of the male terminalia.

\section{Wing morphometry}

Wings of all 444 available specimens were analysed using a landmark-based geometric morphometric approach (Appendix 1). Population analysis was carried out for 418 specimens of 23 populations (Appendix 1, marked with *). Populations with small sample sizes were excluded from the analysis to avoid statistical errors. The left wing of each specimen was removed using micro-scissors and mounted in Hoyer's medium on a microscope slide. Eleven homologous landmarks were digitized at vein intersections or terminations that could be reliably identified and best represented wing shape using TpsDig 2.05 software (Rohlf 2006). Generalized least-squares Procrustes superimposition was first applied to the landmark data to remove non-shape variation in terms of location, scale and orientation, and also to superimpose the objects in a common coordinate system (Rohlf \& Slice 1990; Zelditch et al. 2004). For the wing shape analysis, partial warp scores were calculated (Zelditch et al. 2004). Procrustes superimposition and partial warps were computed using the free IMP software CoordGen7.14 and CVAgen 7.14a (Sheets 2012). MorphoJ v.2.0. software (Klingenberg 2011) was used for visualization of thin-plate spline deformation. Surstylus morphometry

Shape analysis of the posterior part of the left surstylus was carried out on 125 specimens of the M. avidus complex using a semi-landmark geometric morphometric approach (Appendix 2). The posterior part of the left surstylus (Fig. 2A: psl) was removed using a scalpel and placed on its side in glycerol on a microscope slide, and a coverslip was placed on top of the surstylus to immobilize it. Due to a lack of homologous anatomical loci, 30 semi-landmarks were digitized using the 'resample curve by length' option in TpsDig 2.05 software (Rohlf 2006). CoordGen 7.14 with an integrated Semiland module was used for semi-landmark superimposition using a distance-minimizing protocol, which minimizes the shape differences due to the arbitrary nature of semi-landmark positions along the curve (Bookstein 1997; Zelditch et al. 2004).

\section{Statistical analyses}

Principal component analysis (PCA) was used to test variability of wing and surstylus shape without $a$ priori defining groups. Multivariate analysis of variance (MANOVA) and Fisher LSD post-hoc tests were used to test the variability connected with shape differences between species. Additionally, canonical variates analysis (CVA) and discriminant function analysis (DA) were used to test significance in wing and surstylus shape differences, to produce distance matrices and to graphically present results. The phenetic relationships among taxa were determined by UPGMA analysis based on squared Mahalanobis distances computed from the DA applied to wing variables. All statistical analyses were conducted using Statistica for Windows (Statsoft Inc. 2015: version 12).

\section{Molecular analysis}

The 5'-end of the cytochrome c oxidase 1 (COI) gene ('barcode' region) was amplified for three specimens of M. megavidus sp. nov. from Lesvos Island, Greece. DNA was extracted from a leg of each 
AČANSKI J. et al., Species boundaries in the Merodon avidus complex

specimen using a slightly modified SDS Extraction Protocol (Chen et al. 2010). Genomic DNA vouchers are conserved at the Faculty of Sciences, Department of Biology and Ecology, University of Novi Sad (AU827, AU885, AU886) and the Finnish Museum of Natural History, Helsinki (MZH S532). DNA barcodes were amplified with the forward primer LCO (5'-GCTCAACAAATCATAAAGATATTGG-3') and the reverse primer HCO (5'-TAAACTTCAGGGTGACCAAAAAATCA-3') (Folmer et al. 1994). PCR amplifications were carried out in $20 \mu \mathrm{l}$ reaction volumes using the following mix of components: $1 \times$ PCR buffer (Thermo Scientific), $2.5 \mathrm{mM} \mathrm{MgCl}_{2}, 0.1 \mathrm{mM}$ of each nucleotide, $1 \mathrm{U}$ Taq polymerase (Thermo Scientific), 2 pmol of each primer and $50 \mathrm{ng}$ template DNA. PCR conditions were: initial denaturation for $2 \mathrm{~min}$ at $95^{\circ} \mathrm{C} ; 30 \mathrm{~s}$ denaturation at $94^{\circ}, 30 \mathrm{~s}$ annealing at $49^{\circ} \mathrm{C}, 2$ min extension at $72^{\circ} \mathrm{C} / 30$ cycles; and the final extension for $8 \mathrm{~min}$ at $72^{\circ} \mathrm{C}$. Obtained amplicons were purified using the Exo-Sap purification protocol (Thermo Scientific). Forward sequencing using the PCR primer was conducted at the Sequencing Service Laboratory of the Finnish Institute for Molecular Medicine, Helsinki, Finland (FIMM). In order to confirm the taxonomic status of M. megavidus sp. nov. specimens, we created a dataset consisting of 22 DNA barcode sequences, 18 of which represented GenBank-accessioned sequences of M. avidus, M. moenium and M. ibericus Vujić, 2015 (6 sequences per species, accession numbers indicated in Fig. 6, and one sequence for M. megavidus sp. nov. (generated for the Ståhls et al. 2009 study), in addition to three newly-generated M. megavidus sp. nov. DNA barcode sequences in this study). Sequences of Eumerus sulcitibius Rondani, 1868 (Acc. No. KT157875) and Platynochaetus setosus (Fabricius, 1794) (Acc. No. KM224512) (both Merodontini) were used as outgroups. Sequence alignment was conducted using the Clustal W algorithm (Thompson et al. 1994), as implemented in BioEdit (Hall 1999), and final modifications were done by hand. The total length of the dataset after alignment and trimming was 634 nucleotides. We constructed a Neighbour-joining (NJ) tree, and phylogenetic trees using Maximum Likelihood (ML) and Maximum Parsimony (MP) analyses. The NJ and ML trees were constructed using MEGA version 6 (Tamura et al. 2013) using a Tamura-3 parameter model of nucleotide substitution with Gamma correction for among-site variation in substitution rates (estimated in the same software). MP analysis was done using NONA (Goloboff 1999), with the aid of Winclada (Nixon 2002), using the heuristic search algorithm and 1000 random addition replicates (mult x 1000); holding 100 trees per round (hold/100), max trees set to 100000; and applying TBR branch swapping. Bootstrap values were calculated for each tree using 1000 replicates. The genetic relationships among species were also tested using a Median-Joining (MJ) network (Bandelt et al. 1999) generated with Network v4.6.1.3 (available from http://www.fluxus-engineering.com/sharenet.htm) by applying the default settings ( $\varepsilon=0$ and the variable sites weighted equally $=10)$, with additional postprocessing with the maximum parsimony (MP) option.

Pairwise Фst values among species of the Merodon avidus complex were calculated, together with an exact test of population differentiation, using ARLEQUIN 3.5.1.2 (Excoffier \& Lischer 2010). Furthermore, we calculated the genetic distance between defined species using MEGA version 6 (Tamura et al. 2013) in order to estimate times of divergence between genetic clusters based on uncorrected p-distances divided by the pairwise evolutionary rate/MYR as described in Pröhl et al. (2010). We used the pairwise sequence divergence of the COI gene, relative to the mutational rate of $2.3 \%$ per million years, as estimated for various arthropod taxa (Brower 1994). 


\section{Results}

\section{Description of new species}

Family Syrphidae Latreille, 1802

Subfamily Eristalinae Newman 1834

Tribe Merodontini (Edwards, 1915)

Genus Merodon Meigen, 1803

Merodon megavidus Vujić \& Radenković sp. nov. urn:Isid:zoobank.org:act:B2016D80-A7ED-4958-AE91-EE5E6A8C7C51

Figs $2 \mathrm{C}-\mathrm{D}, 3-5$

\section{Diagnosis}

Medium- to large-sized species (13-18mm); black mesoscutum with four white microtrichose longitudinal stripes; tapering orange and black abdomen with white, transverse, microtrichose bands on tergites 2-4 (exceptionally without bands on tergite 2); tarsi reddish-orange dorsally; hind femur medium wide and slightly curved (Fig. 3C-D), with very short pile posteroventrally. Merodon megavidus Vujić \& Radenković sp. nov. belongs to the avidus complex (male genitalia in all species identical in shape, as on Fig. 2). Merodon megavidus sp. nov. can be separated from the other members of the complex by larger size, golden body pile, bright orange colour of the pale parts of legs and extremely short pile on hind femur (Fig. 3C-D). These characteristics contrast with other species from the complex, which have yellow to grayish pale body pile and longer pile on the hind femur (Fig. 3A-B).

\section{Etymology}

The name megavidus refers to the large size (Greek word megas means "large") and great similarity with Merodon avidus.

\section{Type material}

\section{Holotype}

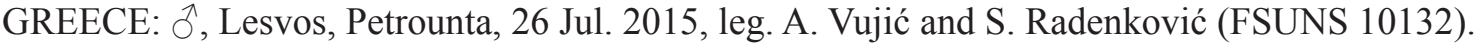
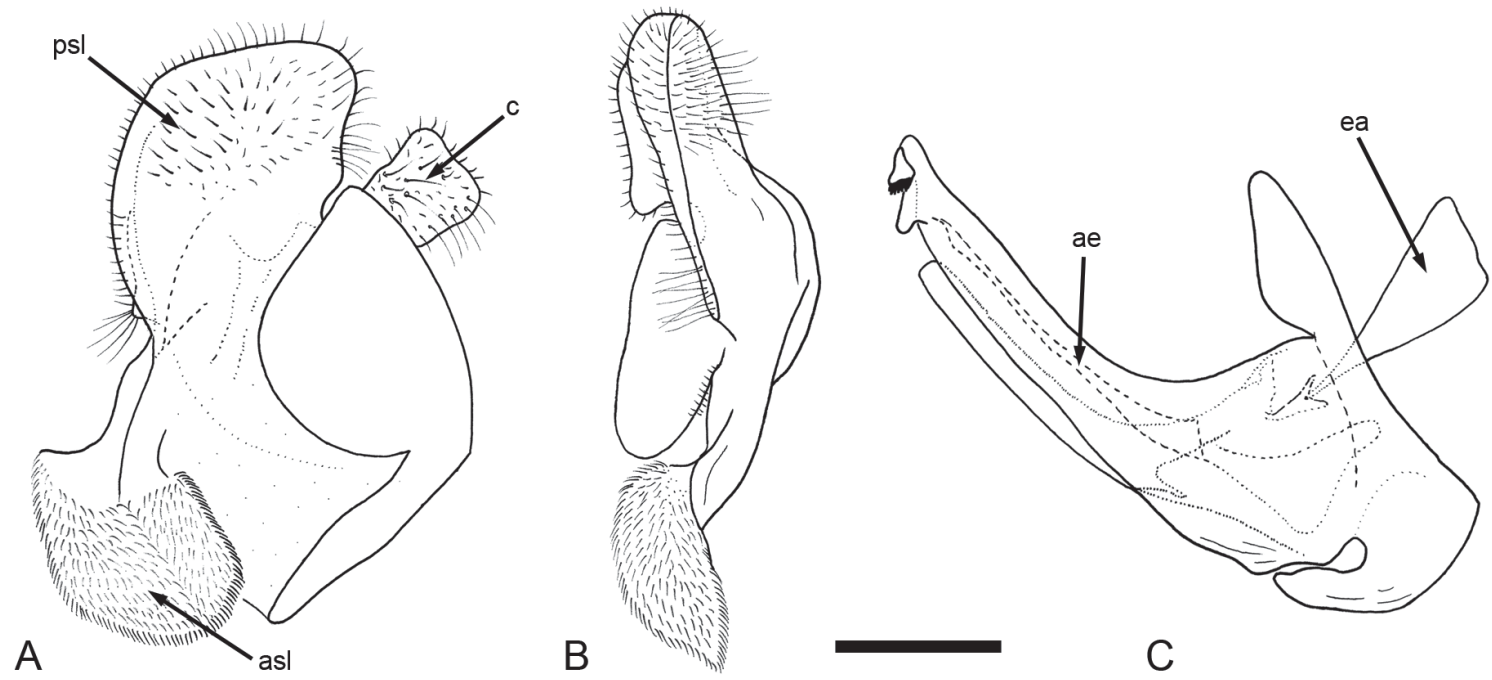

Fig. 2. Merodon megavidus Vujić \& Radenković sp. nov., male genitalia. A. Epandrium, lateral view. B. Left surstylus, anterior view. C. Hypandrium, lateral view. Abbreviations: $\mathrm{psl}=$ posterior surstylus lobe; asl $=$ anterior surstylus lobe; $\mathrm{c}=$ cercus; $\mathrm{ae}=$ aedeagus; $\mathrm{ea}=$ ejaculatory apodeme. Scale bar $=0.5 \mathrm{~mm}$. 


\section{Paratypes}

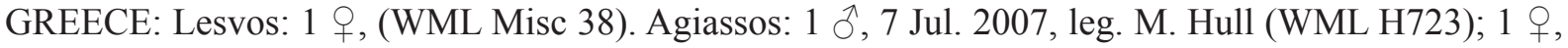
8 Jun. 2003, leg. G. Ståhls (FSUNS 04385); 1 q, 8 Jun. 2003, leg. G. Ståhls (MZH); 1 ô, 16 Jun. 2004,

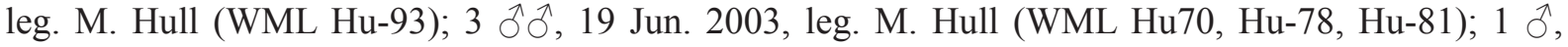

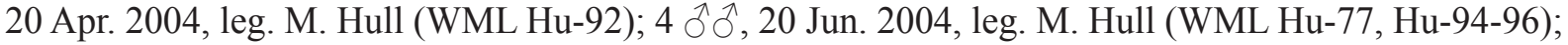

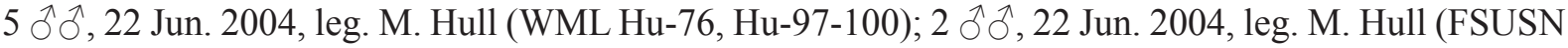

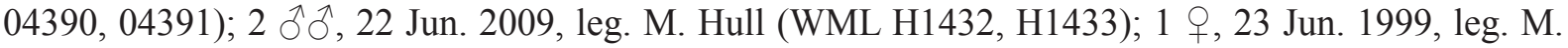

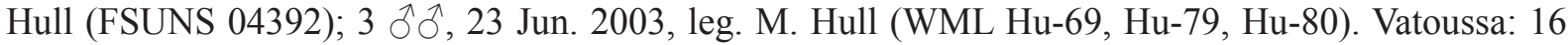

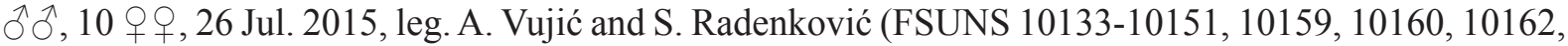

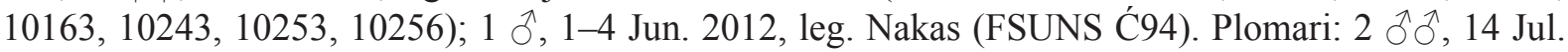
2004, (FSUNS 02325, 03966); 1 đ̊, 14. Jul. 2004, leg. H. Dahm (S532).
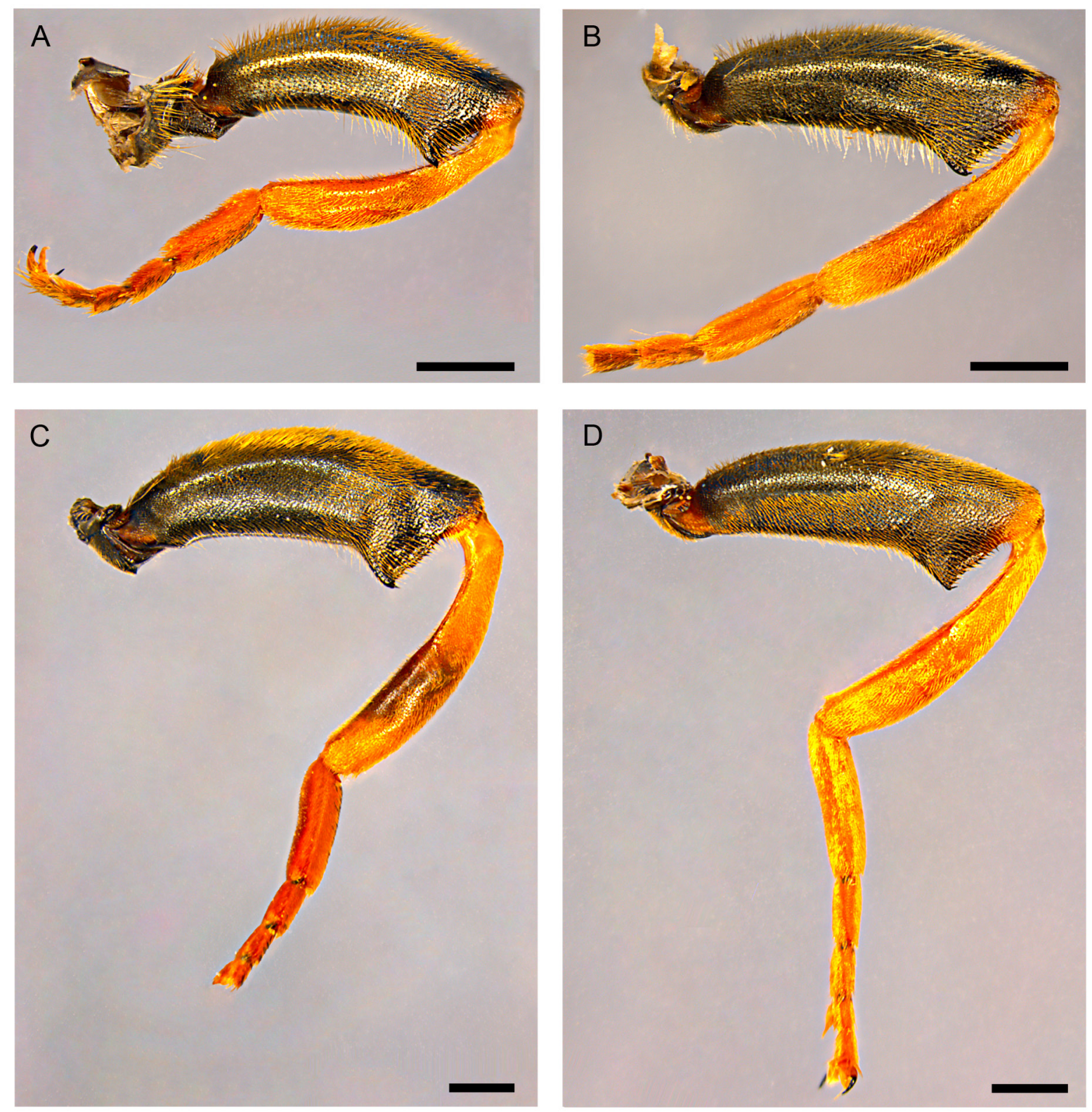

Fig. 3. Hind leg, lateral view. A-B. Merodon avidus (Rossi, 1790). A. ̊. B. ․ . - C-D. M. megavidus

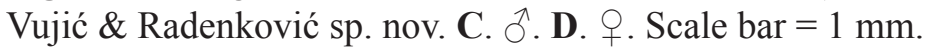




\section{Description}

Male (Figs 2C, 3, 4A, 5A)

HeAD (Fig. 4A). Antenna (Fig. 4A) orange, first flagellomere 1.8-2.0 times as long as wide, 2.0 times longer than pedicel, concave, apex acute; arista: second, third and basal part of fourth flagellomeres pale, fourth flagellomere dark brown in apical $2 / 3$ and thickened basally, 1.4 times longer than first flagellomere; with short, dense microtrichia. Face and frons black, covered with long golden pile and silver, dense microtrichia. Oral margin shiny black, except for the lateral microtrichose areas (Fig. 4A). Vertical triangle isosceles, shiny black except in front of the anterior ocellus that has pale microtrichia, covered with long orange pile except for black pile on the ocellar triangle. Ocellar triangle equilateral. Eye contiguity about 12 ommatidia long. Vertical triangle: eye contiguity: ocellar triangle $=1.5: 0.7$ : 1. Eye pile dense, white. Occiput with orange pile, along the eye margin with dense white microtrichia and posteriorly with metallic, bluish-greenish lustre.

Thorax. Mesoscutum and scutellum black with bronze lustre, covered with relatively long, dense, erect golden pile. Side of mesoscutum above wing-base with a patch of black pile. Mesoscutum with two lateral and two submedian, longitudinal, white microtrichose stripes. Proepimeron, posterior anepisternum, anteroventral and posterodorsal part of katepisternum, anepimeron, metasternum and katatergite with long golden pile and grey-green microtrichia. Wing hyaline, with dense microtrichia; veins dark brown except for light brown C, Sc and R1. Calypter pale yellow. Haltere with light brown pedicel and yellow capitulum. Legs orange, except for the black basal $3 / 4$ of the front- and mid-femora. Pile on legs golden. Hind femur (Fig. 3C) moderately thickened and curved, about 3.6 times as long as deep. Pile on hind femur very short.

ABdomen (Fig. 5A). Dark with white microtrichose bands, tapering, 1.4 times longer than mesonotum (including scutellum). Tergites orange and reddish except for black tergite 1 and central parts of tergites 2-3 (and 4) (Fig. 5A); orange-reddish parts of variable size on tergite 3 and 4, laterally and along microtrichose bands. Tergites $2-4$ each with a pair of white microtrichose marks (exceptionally absent only on tergite 2); tergites 3-4 with wide, oblique bands (Fig. 5A). Pile on tergites golden. Sternites translucent, orange to brown towards the tip of the abdomen, covered with long yellow pile.
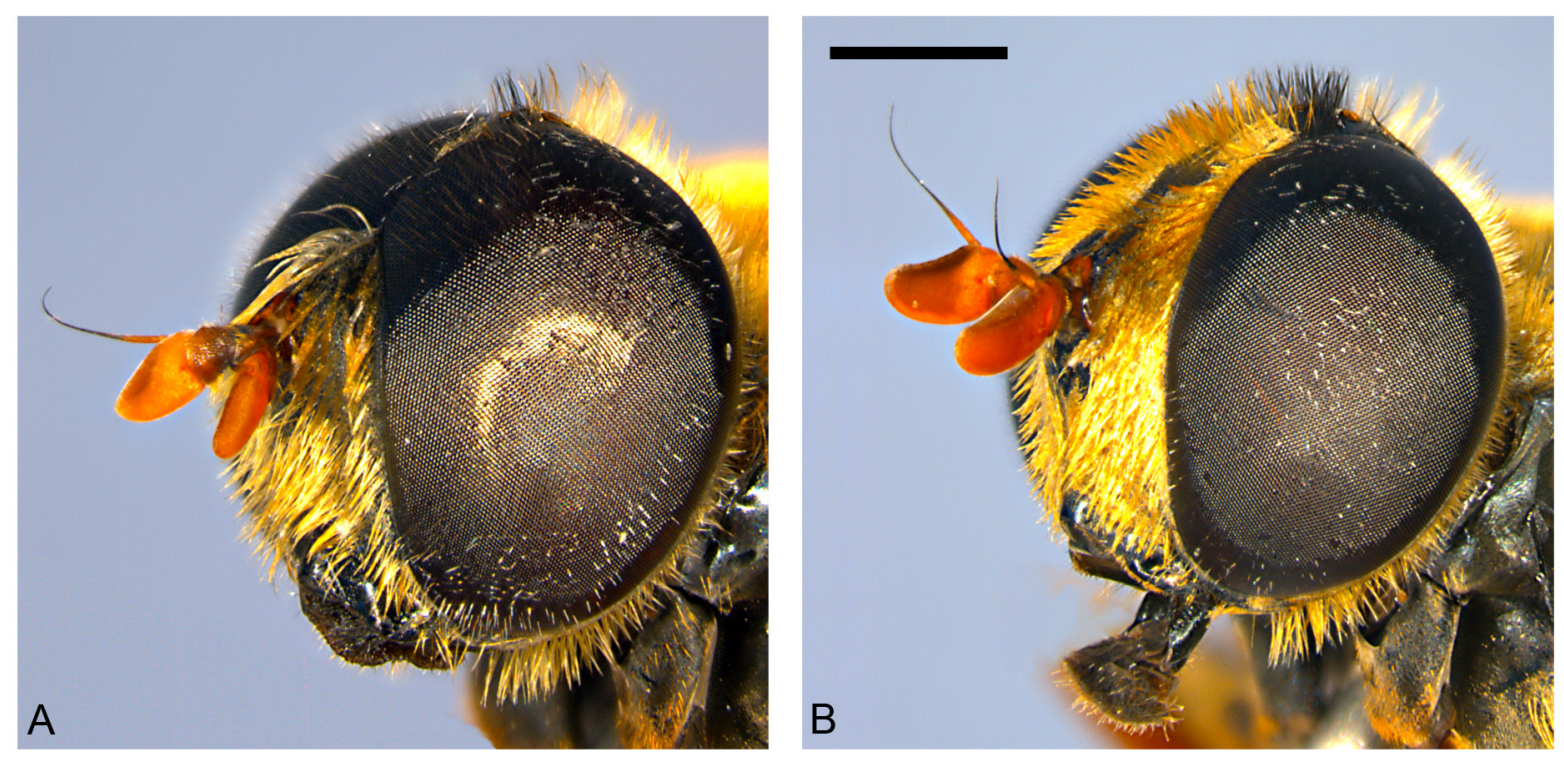

Fig. 4. Merodon megavidus Vujić \& Radenković sp. nov., head, antero-lateral view. A. §̊. B. ๆ. Scale bar $=1 \mathrm{~mm}$. 
Male genitalia (Fig. 2). Similar to all species of the M. avidus complex. Anterior lobe of surstylus broad and hairy (Fig. 2A-B); posterior lobe of surstylus ellipsoidal at ventral margin (Fig. 2A-B); cercus rectangular, without prominences (Fig. 2A). Hypandrium elongate and sickle-shaped, without lateral projections (Fig. 2C); lingula long (Fig. 2C).

Female (Figs 2D, 4B, 5B)

Similar to the male except for typical sexual dimorphism and for the following characteristics: first flagellomere broader and longer; frons with two wide (about 0.34 width of frons) lateral silver microtrichose longitudinal stripes; frons in the widest part about 0.25 width of head; white microtrichose longitudinal stripes on mesoscutum more visible; broad stripe of black pile between wing bases; tergites predominately red except for tergite 1 and darkened parts of tergites 2-4 in some specimens (Fig. 5B); white, microtrichose, transverse bands on tergites 3-4 (Fig. 5B); tergites 2-3 with black pile on dark parts; white microtrichose bands solely with pale pile.

\section{Remarks}

This species was mentioned as Merodon sp. nova 2 in Ståhls et al. (2009) and Ricarte et al. (2012). Ståhls et al. (2009) assumed it to be a distinct species based on the different COI barcode sequences
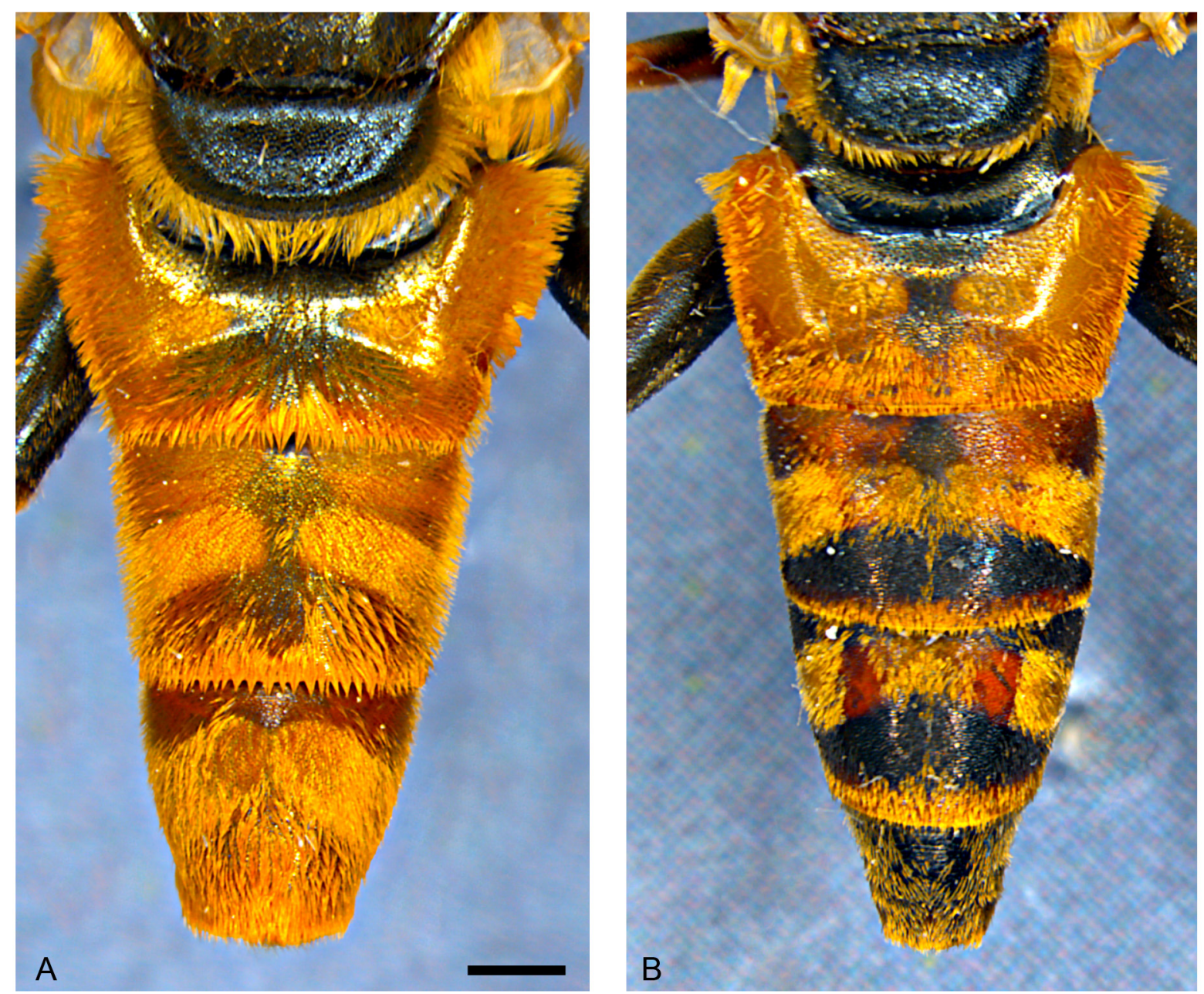

Fig. 5. Merodon megavidus Vujić \& Radenković sp. nov., abdomen, dorsal view. A. $\widehat{o}$. B. $q$. Scale bar $=$ $1 \mathrm{~mm}$. 
obtained from two specimens morphologically similar to M. avidus taken from Lesvos Island. In the key prepared as supporting material for Ståhls et al. (2009), M. avidus and M. sp. nova 2 key out together, without any morphological differences being described.

\section{Distribution and habitat data}

Lesvos Island (Greece). Maquis shrubland.

\section{Species delimitation}

\section{Molecular data}

Merodon megavidus sp. nov. clearly differs from other members of M. avidus complex based on our barcoding fragment of COI. All conducted phylogenetic analyses resulted in similar tree topologies (Figs 6-7; Appendix 3). Sequences from the Merodon avidus complex formed three separate clusters: one cluster represented M. ibericus, a second comprised all M. megavidus sp. nov. sequences with highly-significant bootstrap values (100), the third grouped sequences of M. avidus and M. moenium together. All four M. megavidus sp. nov. sequences were identical, defining one haplotype unique to the species. The number of mutational steps between M. megavidus sp. nov. and M. avidus is 14, with 13 and 22 mutational steps between M. megavidus sp. nov. and M. moenium and M. ibericus, respectively (Fig. 8).

Our UPGMA tree based on genetic distances among species revealed genetic relationships among four taxa of the Merodon avidus complex that support and strengthen the branch positions in wing and surstylus phenograms described below (see Fig. 9).

Significant pairwise genetic divergence ( $\phi$ st value) was detected in each pairwise comparison between M. megavidus sp. nov. and each of the other species M. ibericus, M. avidus and M. moenium $(0.420,0.492$ and 0.529 , respectively). Sequence divergence (uncorrected $\mathrm{p}$ distance) of the COI gene was used to

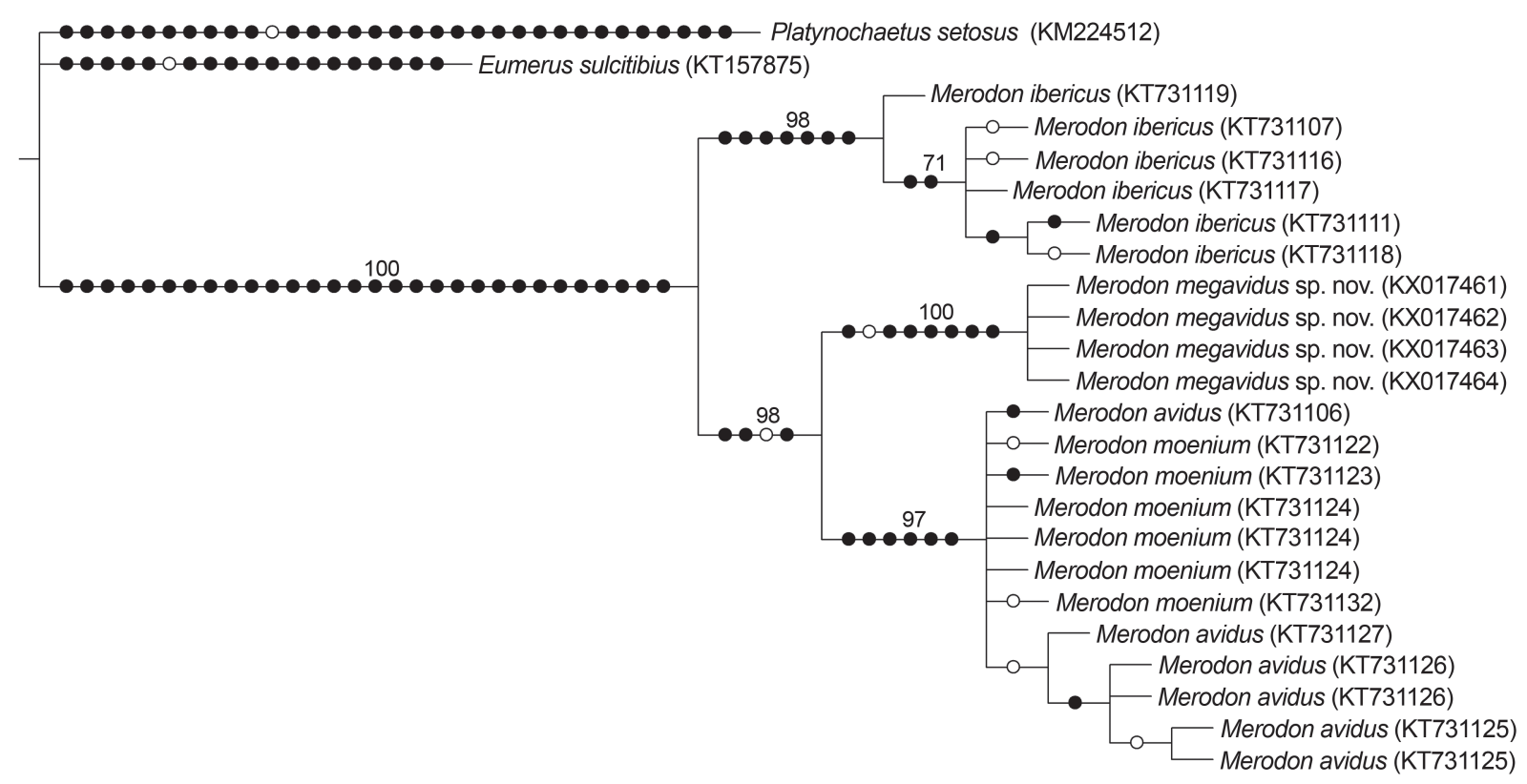

Fig. 6. Maximum parsimony strict consensus tree based on DNA barcode COI sequences. Length 136 steps, Consistency Index $(\mathrm{CI})=93$, Retention Index $(\mathrm{RI})=95$. Filled circles denote unique changes, open circles non-unique. 
AČANSKI J. et al., Species boundaries in the Merodon avidus complex

Table 1. Below diagonal - pairwise p distances; above diagonal - estimated divergence times in years.

\begin{tabular}{lcccc}
\hline & M. megavidus sp. nov. & M. ibericus & M. avidus & M. moenium \\
\hline M. megavidus sp. nov. & - & 826.000 & 521.000 & 478.000 \\
M. ibericus & 0.038 & - & 800.000 & 760.000 \\
M. avidus & 0.024 & 0.037 & - & 87.000 \\
M. moenium & 0.022 & 0.0035 & 0.004 & - \\
\hline
\end{tabular}

assess relative divergence times between the four Merodon taxa (Table 1), indicating an initial separation of $M$. ibericus from the rest of the complex around $800 \mathrm{ky}$ BP. Divergence between M. megavidus sp. nov. and M. avidus/M. moenium occurred around $500 \mathrm{ky}$ BP. The most recent separation happened between M. avidus and M. moenium, around $87 \mathrm{ky} \mathrm{BP.}$

\section{Geometric morphometrics - wing shape analysis}

Principal component analysis conducted on 444 specimens of the M. avidus complex revealed six principal components (PC) that together explained $63.9 \%$ of total wing shape variability. A MANOVA with Fisher LSD post-hoc test showed that variability reflected shape changes among the investigated

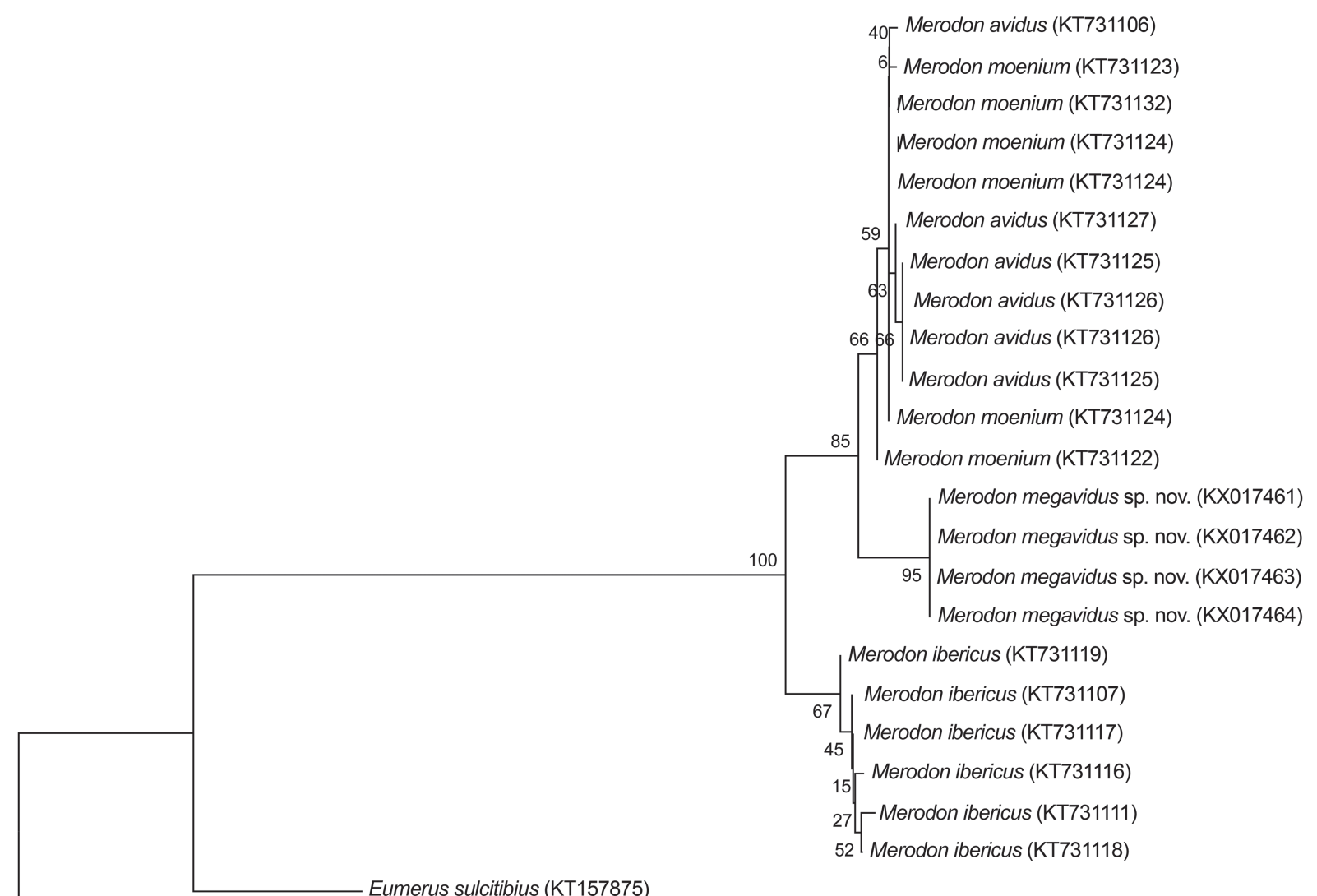

Platynochaetus setosus (KM224512)

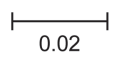

Fig. 7. Maximum Likelihood tree based on a 5' fragment of COI mtDNA sequences from the Merodon avidus complex. Bootstrap values (1000 replicates) are shown next to the branches. The tree is drawn to scale, with branch lengths proportional to the number of substitutions per site. 
species in all six PCs (MANOVA: $\mathrm{F}_{18,1230}=38.56 ; \mathrm{p}<0.00000$ ). Further, DA showed that all species differ highly significantly in wing shape $(\mathrm{p}<0.00000)$, and correctly classified species with an overall classification success of $90 \%$. All specimens of M. megavidus sp. nov. were correctly classified, while the lowest classification success was for M. ibericus (78\%). Specimens belonging to M. avidus were correctly classified with $89 \%$ and M. moenium with $93 \%$ certainty. Canonical analysis produced three canonical axes (CV) related to wing shape differences (Fig. 10). CV1 separated M. avidus from M. moenium with $58 \%$ of total variation (CV1: Wilks' Lambda $=0.145440 ; \chi 2=832.8937 ; \mathrm{p}<0.00000$ ), while CV2 separated M. avidus and M. moenium from M. megavidus sp. nov. and M. ibericus with $27 \%$ of total variation (CV2: Wilks' Lambda $=0.388320 ; \chi 2=408.6395 ; \mathrm{p}<0.00000)$ (Fig. 10A). Merodon moenium and M. ibericus were clearly separated according to CV3 (CV3: Wilks' Lambda $=0.698600$; $\chi 2=154.9484 ; \mathrm{p}<0.00000$ ) (Fig. 10B). The phenogram constructed based on squared Mahalanobis distances clearly depicts that $M$. avidus and $M$. moenium have more similar wing shapes than $M$. ibericus and M. megavidus sp. nov. (Fig. 11). Differences in wing shape among species are depicted in Figure 12, but have been exaggerated five-fold to make them more visible.

Additionally, the phenogram constructed based on squared Mahalanobis distances of wing shape showed that all 26 analysed populations grouped according to species (Fig. 13).

\section{Geometric morphometrics - surstylus shape}

PCA of surstylus shape revealed seven PC, of which the first six were connected with shape differences among species (MANOVA: $\mathrm{F}_{21,333}=5.280113 ; \mathrm{p}<0.00000$ ). DA showed that all species differ highly significantly in surstylus shape $(\mathrm{p}<0.00000)$. All specimens of M. avidus and M. megavidus sp. nov. were correctly classified (100\%), while only two specimens of M. ibericus and M. moenium were misclassified (97\%). CVA found three CVs connected with shape change (Fig. 14). CV1 clearly separated M. avidus from $M$. megavidus sp. nov., M. moenium and $M$. ibericus and represented $53 \%$ of total shape variability $(C V 1$ : Wilks' Lambda $=0.013392 ; \chi 2=405.4285 ; \mathrm{p}<0.00000)$ (Fig. 14A). The second canonical axis clearly separated M. megavidus sp. nov. from M. moenium and M. ibericus and was responsible for $25 \%$

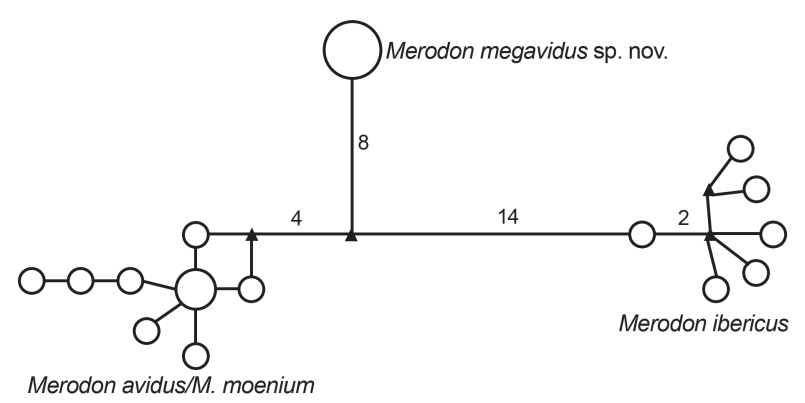

Fig. 8. Median-joining network of the mtDNA 5'-end of the COI gene. Circle sizes are proportional to haplotype frequencies. Each branch represents one mutational step; if more than one mutational step is present, it is denoted by the given number.

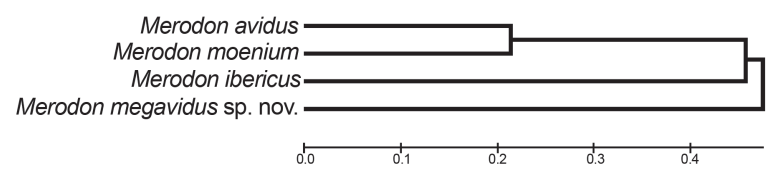

Fig. 9. UPGMA tree based on pairwise genetic distances for four species from the Merodon avidus complex. 

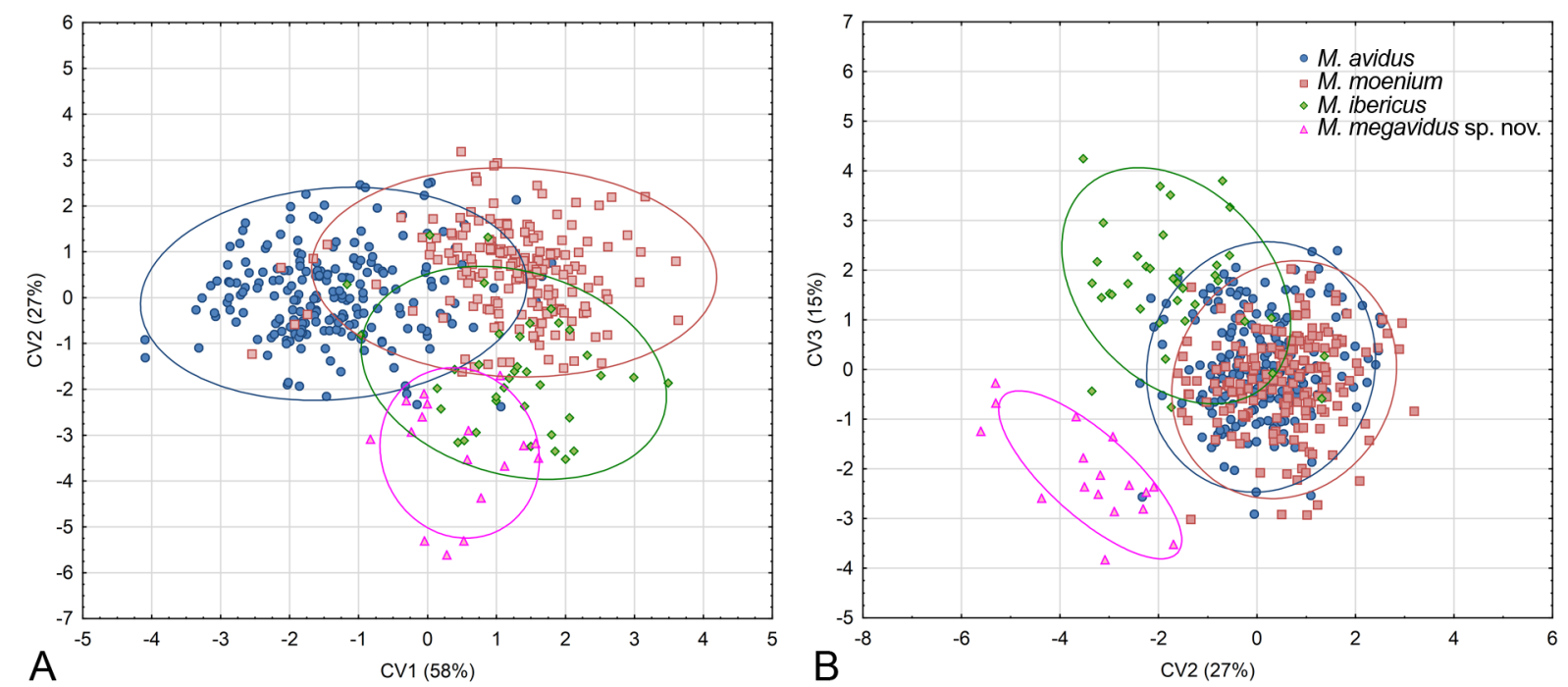

Fig. 10. Differences in wing shape among species of the M. avidus complex. A. Scatter plot of individual scores of CV1 vs CV2. B. Scatter plot of individual scores of CV2 vs CV3.

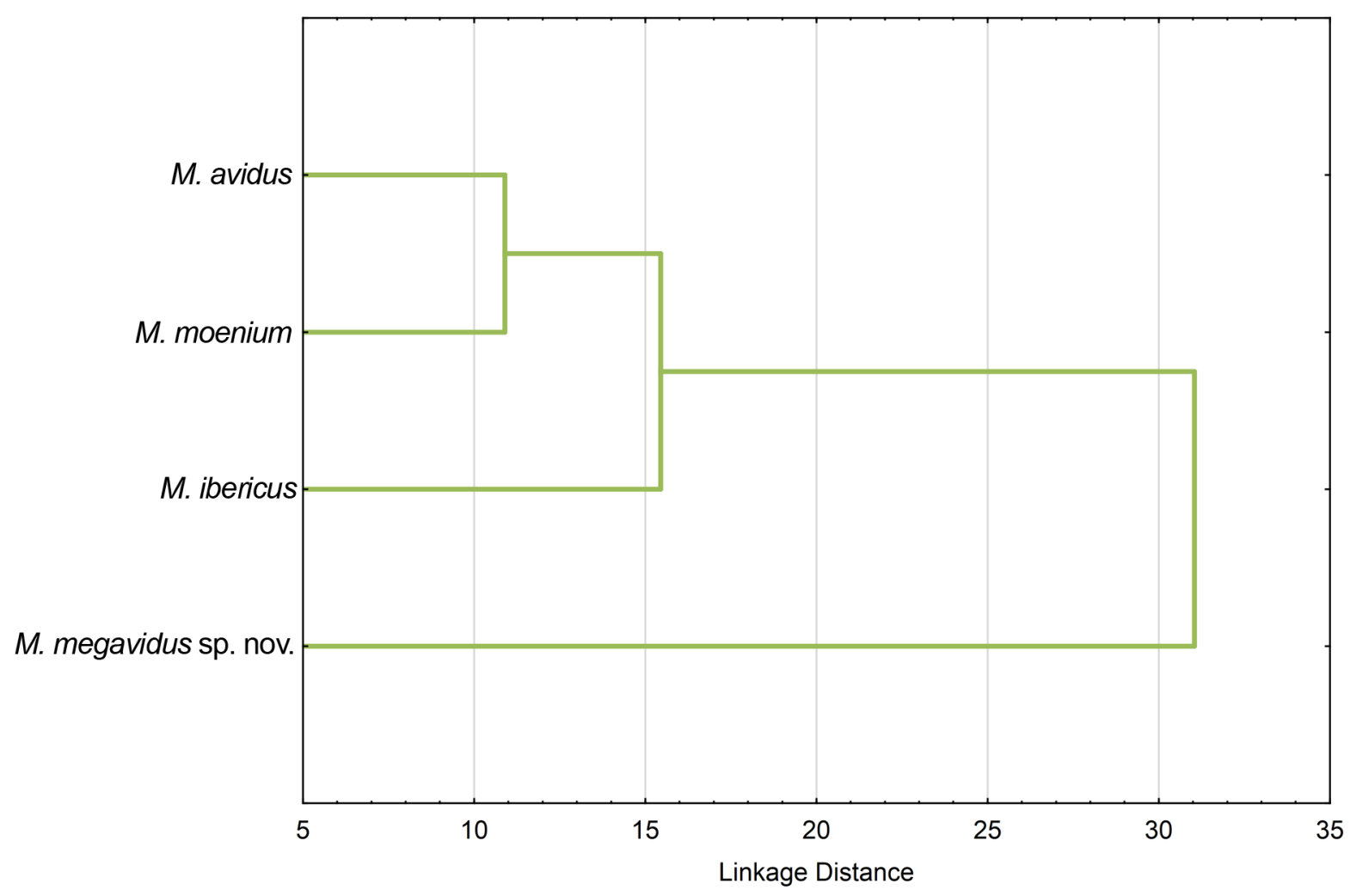

Fig. 11. UPGMA phenogram constructed using the squared Mahalanobis distances of wing shape for species of the M. avidus complex. 
of the variability (CV2: Wilks' Lambda $\left.=0.086702 ; \chi^{2}=229.8565 ; \mathrm{p}<0.00000\right)$ (Fig. 14A). Merodon moenium and M. ibericus were separated by CV3, with $18 \%$ of total shape variability (CV3: Wilks' Lambda $=0.346752 ; \chi^{2}=99.5597 ; \mathrm{p}<0.000305$ ) (Fig. 14B). According to the phenogram constructed based on squared Mahalanobis distances, M. megavidus sp. nov. has a more distinct surstylus shape, while the surstyli of M. moenium and M. ibericus are the most similar (Fig. 15A). The main shape differences among all three species lie in the posterior margin of the posterior part of the surstylus lobe (Fig. 15A).

\section{Discussion}

Differentiation and taxonomic status of the cryptic species of the Merodon avidus complex has been controversial for many years. An initial molecular analysis showed that M. avidus is a genetically and geographically structured taxon with at least two cryptic species, which were designated as M. avidus A and M. avidus B (Milankov et al. 2001). Further investigations based on the mtDNA COI marker expanded on this by finding two additional cryptic species from the Iberian Peninsula (M. bicolor Gil Collado, 1930, now M. ibericus) and Lesvos Island (Greece) (M. sp. nova 2, now M. megavidus sp. nov.) (Milankov et al. 2009, Ståhls et al. 2009). In Milankov et al. (2009), wing shape analysis could not distinguish taxa that could be differentiated by allozyme loci, even though these taxa differed in wing size. Also, they found a great deal of similarity between allopatric metapopulation pairs of M. avidus
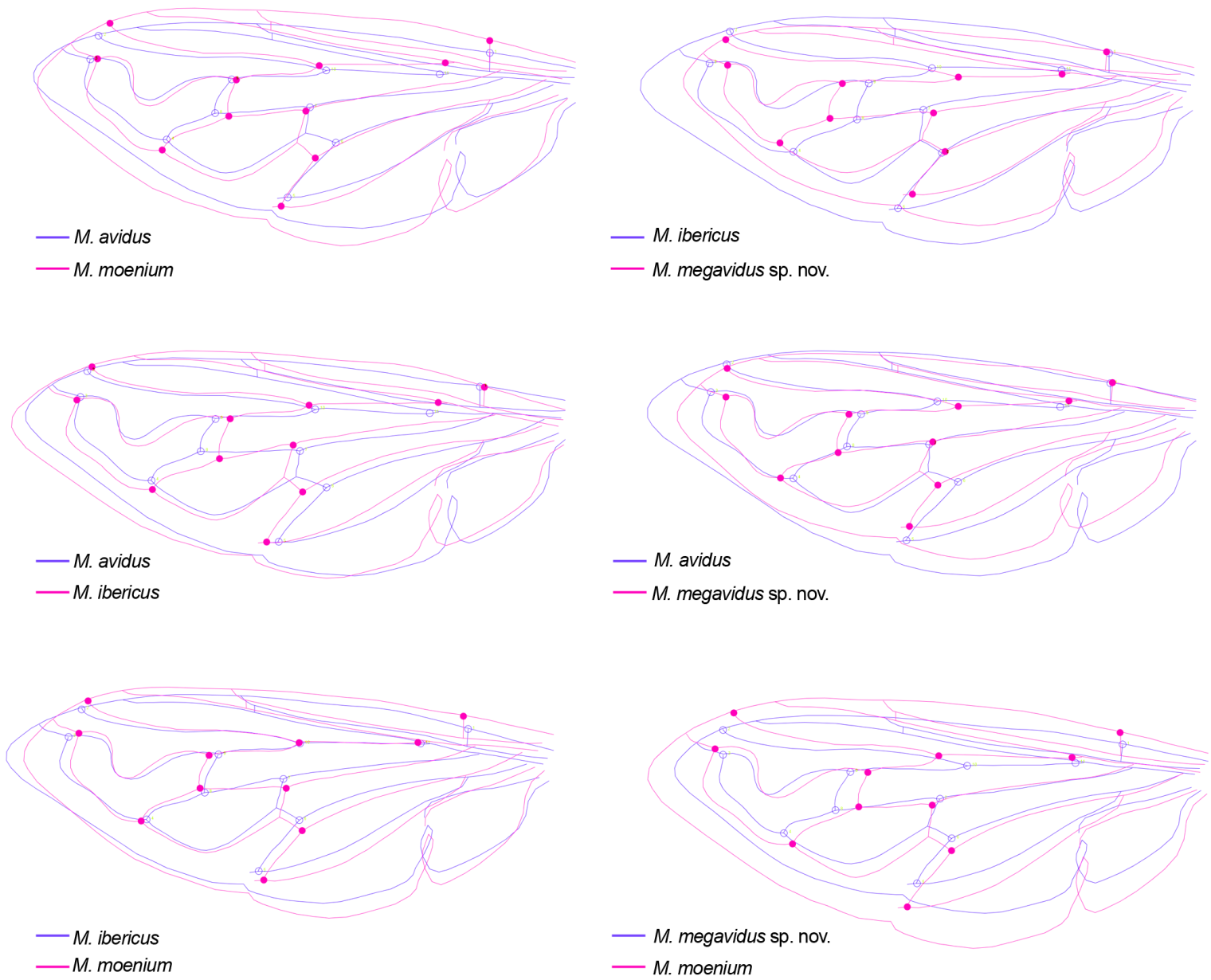

Fig. 12. Thin-plate spline deformation grids showing wing shape differences between analysed species. Differences between the species have been exaggerated five-fold to make them more visible. 
A and M. avidus B; populations of M. avidus A from Macedonia and the Pannonian plain overlapped with M. avidus B populations from Durmitor, Stara Planina and Kopaonik in terms of wing shape. Only a population of M. avidus A from Morinj (Montenegro) was clearly separated from other populations. Subsequent analysis showed that this substantial overlap in wing shape was a result of incorrect species identifications due to the morphological similarities between spring generations of $M$. avidus and M. moenium (Popović et al. 2015). Previously, it had been considered that M. moenium (M. avidus B) was a species distributed on mountainous regions of the Balkan Peninsula. However, it is now known that while M. moenium is predominantly distributed in the continental parts of Europe, it also occurs in some parts of the Mediterranean basin and the Black Sea coast, where it can occur sympatrically with M. avidus. Further, allozyme analysis of morphologically different spring and autumn generations from Umag (Croatia) clarified this misclassification issue by showing that both morphotypes belonged to M. avidus (Popović et al. 2015).

Our molecular analysis using the barcoding COI fragment for an additional three specimens from Lesvos Island supports the presence of a morphologically cryptic taxon (M. megavidus sp. nov.), previously revealed by Ståhls et al. (2009). All our phylogenetic analyses placed M. megavidus sp. nov. as a separate independent cluster from M. ibericus and the M. avidus/M. moenium branch (Figs 6-9). According to estimated divergence times, all diversification occurred in the Pleistocene (2.6 to 0.0117 MYA). This geological epoch was marked by repeated (at least 20) glacial and interglacial periods, which influenced speciation and the distributions of many recent taxa in Europe (Julius \& Kukla 1977; Martinson et al. 1987; Perissoratis \& Conispoliatis 2003). Recent studies have revealed many examples of insect species that have altered their ranges and/or evolved as a response to repeated isolation during glacial-interglacial cycles across three large peninsulas of Southern Europe (Hewitt 2001; Konstantinov et al. 2009; Dapporto 2010; Nicholls et al. 2010; Zhu et al. 2013).

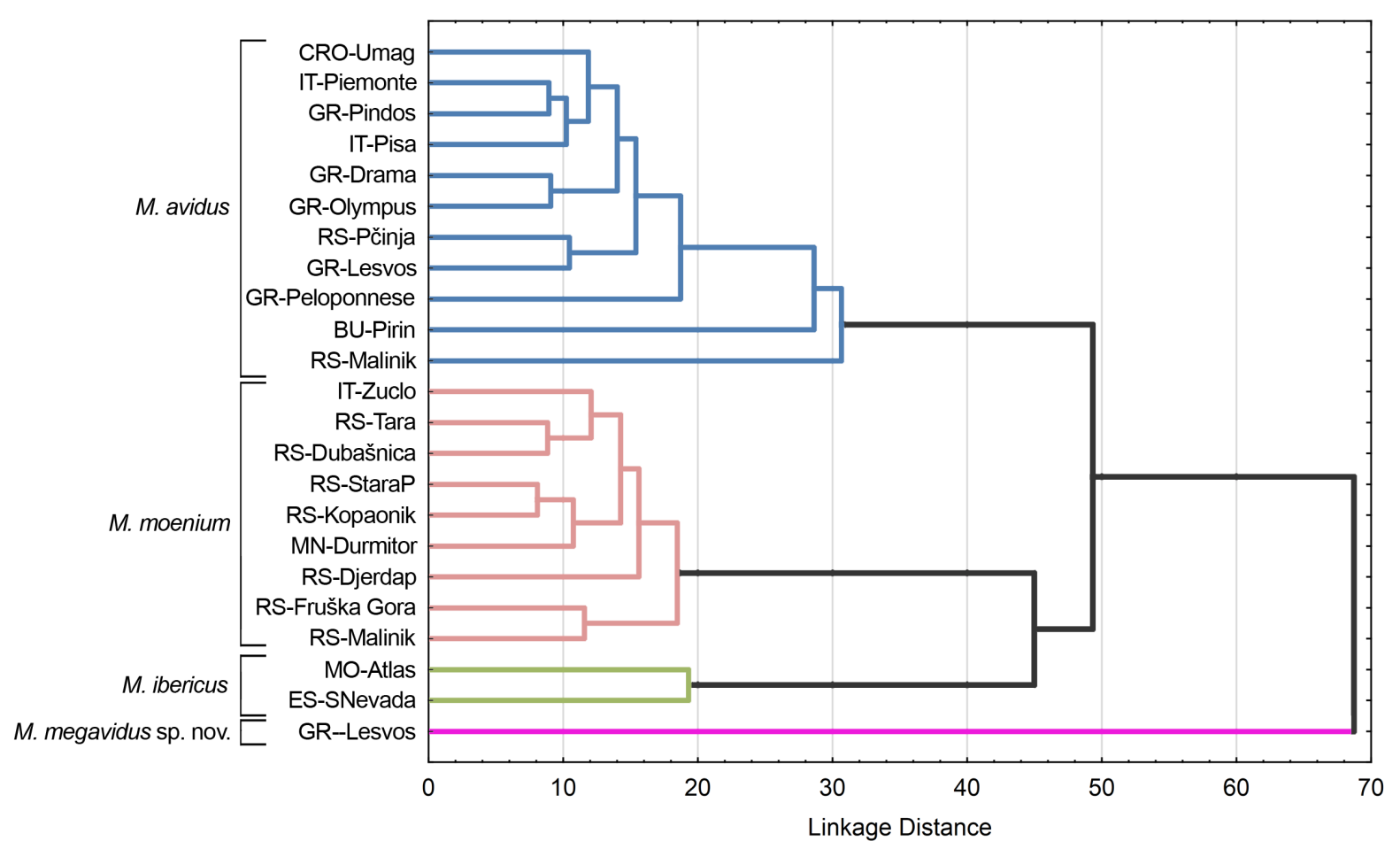

Fig. 13. UPGMA phenogram constructed using squared Mahalanobis distances of wing shape for populations of species of the M. avidus complex. 
The first mitochondrial diversification in the M. avidus complex took place in the Calabrian stage of the Early Pleistocene (around 800 ky BP), when M. ibericus diverged from a common ancestor. The GünzMindel interglacial corresponds to the approximate period when separation of M. megavidus sp. nov. from the M. avidus/M. moenium lineage occurred. The most recent diversification, i.e., between M. avidus and M. moenium, most likely took place at the end of the Riss-Würm interglacial or the beginning of the Würm glaciation period. The low species resolution ability of the 3' and 5' fragments of COI to separate the M. avidus and M. moenium lineages (Milankov et al. 2009; Popović et al. 2014, 2015) can be explained by recent speciation and by the founder effect associated with postglacial recolonization of northern Europe (Shikano et al. 2010). Both species share an identical haplotype of the COI 3'-end (Popović et al. 2014), although the 5'-end fragment haplotypes of DNA barcodes are not shared, they give low support in cluster analyses (Popović et al. 2015).

The most probable scenario for postglacial colonization of Europe is expansion of the M. avidus and M. moenium lineages from the Balkan Peninsula into Central Europe (a "grasshopper" pattern of colonization according to Hewitt 1999). The Pyrenees acted as a significant geographical barrier preventing the dispersal of $M$. ibericus to other European areas.

Our geometric morphometric analyses show that all investigated species of the M. avidus complex can be successfully discriminated based on wing and surstylus shape. The high overall success rate of classification indicates that wings, and especially surstylus shape, have meaningful interspecific discriminatory power. It is important to emphasize that, contrary to previous geometric morphometric studies, we found highly significant differences in wing shape between M. avidus and M. moenium. The phenogram based on squared Mahalanobis distances for wings is congruent with the UPGMA tree based on genetic distances among species. Wing shape, as a highly heritable structure, has greater importance in insect taxonomy than wing size (Birdsall et al. 2000), which has been confirmed by earlier studies of hoverflies in which wing shape has been successfully used for identification and delimitation of species (Vujić et al. 2013b; Nedeljković et al. 2013, 2015).

Additional evidence for species distinctiveness is provided by the highly significant differences in surstylus shape between M. avidus, M. ibericus, M. megavidus sp. nov. and M. moenium. The main differences in surstylus shape are connected to the posterior margin of the posterior part of the surstylus
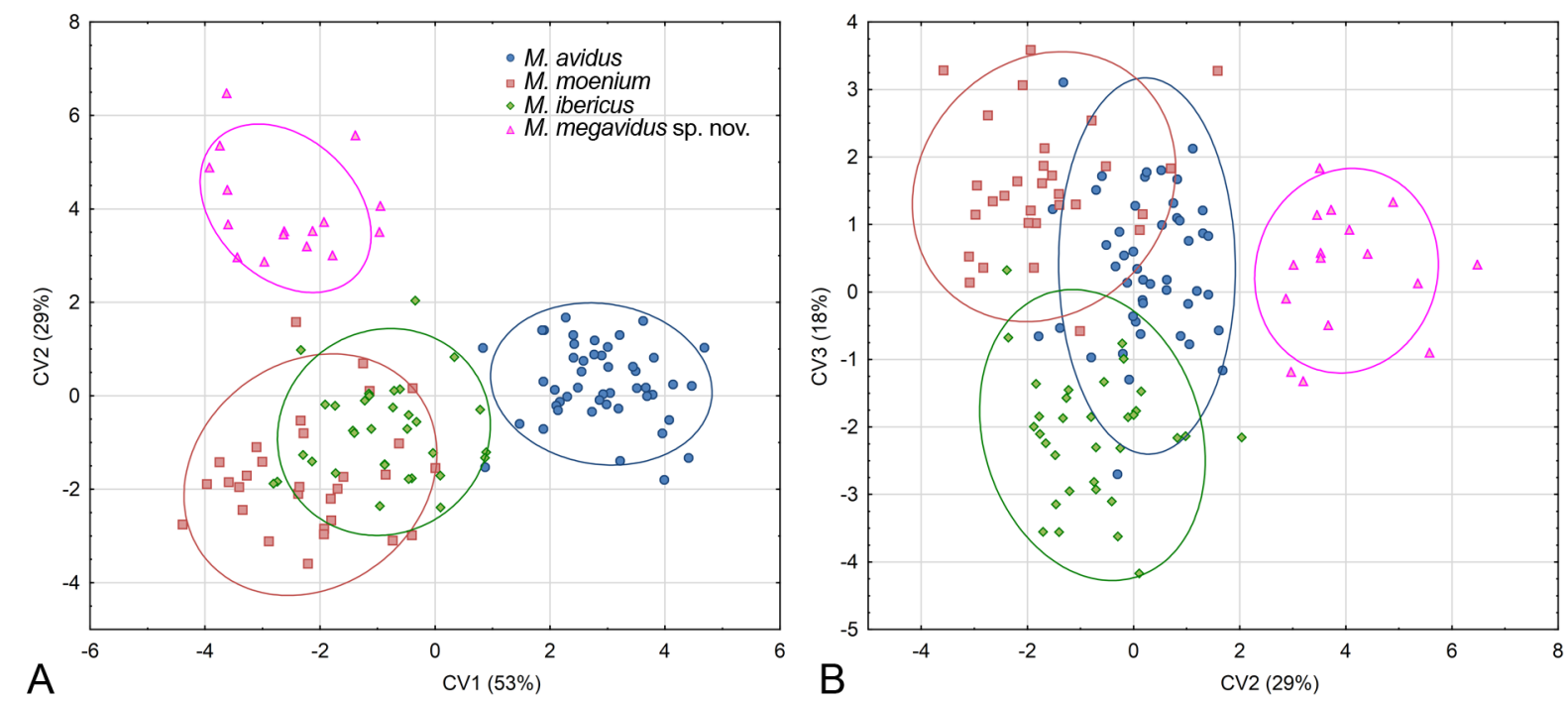

Fig. 14. Differences in the posterior part of the surstylus among species of the M. avidus complex. A. Scatter plot of individual scores of CV1 vs CV2. B. Scatter plot of individual scores of CV2 vs CV3. 
lobe, which is involved in gripping the female during copulation. It could be hypothesized that these shape differences contribute to a mechanism of sexual isolation, especially since M. avidus has a distinct surstylus shape compared to partly sympatric M. moenium. Although the exact mechanism of sexual isolation in Syrphidae is not known, traditionally the shape of male genitalia is deemed a significant mechanism of isolation between species (Rotheray \& Gilbert 2011). Given that the morphology of male genital structures is considered one of the fastest evolving traits in animal groups with internal fertilization (Soto et al. 2013), and that insect genitalia are conspicuously variable even in closely related taxa that are otherwise morphologically very similar (Hosken \& Stockley 2004), we assert that significant differences in surstylus shape is strong evidence for species delimitation. Recent studies have found that natural and sexual selection (and their interaction) caused insect genital evolution (Hasson et al. 2009; House et al. 2013), and that the degree of morphological differences in the structures of genitalia is associated with geographic distance (Soto et al. 2013). Despite their recent speciation and geographic proximity, M. avidus does not exhibit a similar surstylus shape to M. moenium. Other studies have found that other factors, such as specific host plant relationships Soto (2012) or sexual selection (Hosken \& Stockley 2004), may promote further evolution in genital morphology.

Our population-level morphometric analysis of wing shape is in concordance with species delimitation findings. All populations clustered according to species. Furthermore, in this analysis, M. megavidus sp. nov. from Lesvos Island is distinct from all other species and/or populations, and it is important to underline that this taxon was clearly differentiated from population(s) of M. avidus also from Lesvos Island.

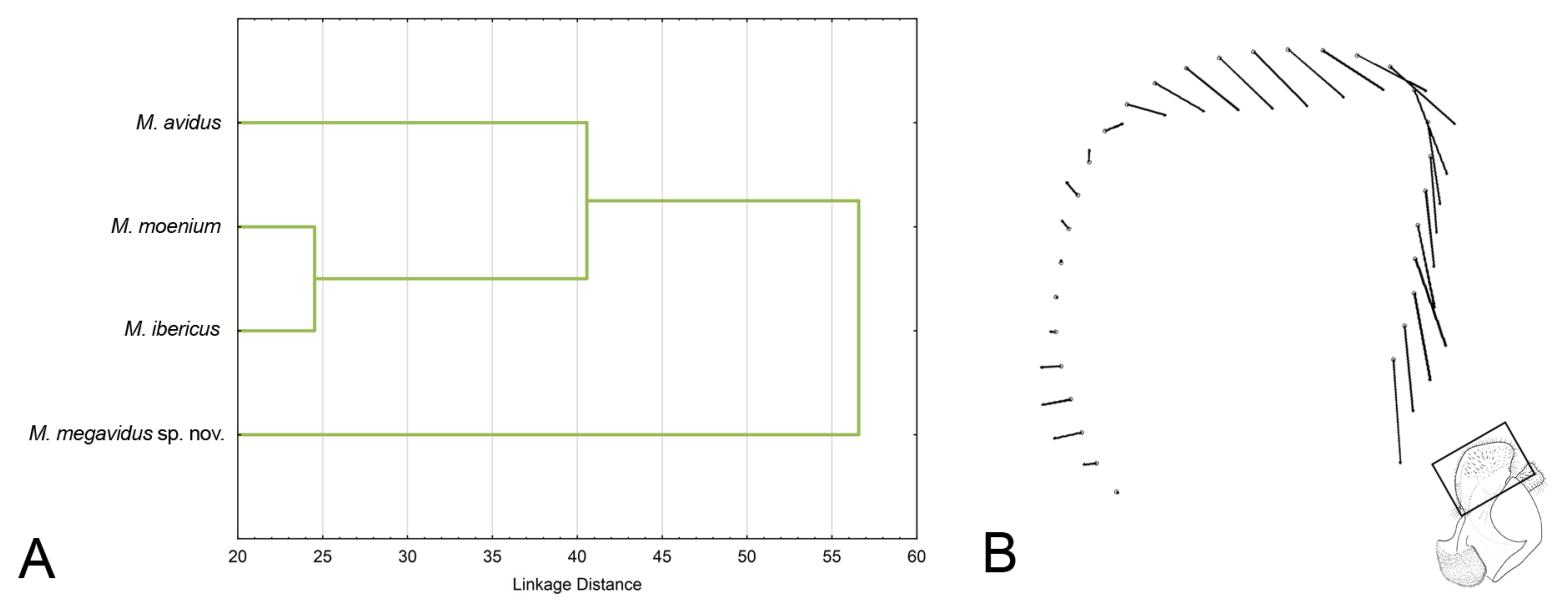

Fig. 15. Differences in the posterior part of the surstylus among species of the M. avidus complex. A. UPGMA phenogram constructed using squared Mahalanobis distances. B. Thin-plate spline deformation grids showing overall shape differences between analysed species.

\section{Acknowledgements}

We thank the curators of the several museums listed above in the "Studied material" section that facilitated visits and loaned specimens for study. We thank John O'Brien for English revision. Financial support was provided by the Serbian Ministry of Education, Science and Technological Development (projects OI173002, III43002 and OI1613001), the Provincial Secretariat for Science and Technological Development (project 'Genetic resources of agro-ecosystems in Vojvodina and sustainable agriculture'), 
the Transnational Access to Research Infrastructures activity in the FP7 of the EC (ExpeER project, TA visit 'STEPS'), the FP7 EU project, Innosense, and National Strategic Reference Framework (NSRF) Research Funding Program: THALES.

\section{References}

Andrić A., Šikoparija B., Obreht D., Đan M., Preradović J., Radenković S., Pérez-Bañón C. \& Vujić A. 2014. DNA barcoding applied: identification of the larva of Merodon avidus (Diptera: Syrphidae). Acta Entomologica Musei Nationalis Praga 54 (2): 741-757. http://zoobank.org/urn:lsid:zoobank. org:pub:5CB81C03-0C5F-4220-AD2B-1C97F74C30D3

Andrić A., Kočiš-Tubić N., Rat M. \& Obreht-Vidaković D. 2015. Diversity and genetic structure of Ornithogalum L. (Hyacinthaceae) populations as revealed by RAPD-PCR markers. Genetika 47 (1): 275-288. http://dx.doi.org/10.2298/GENSR1501275A

Bandelt H.J., Forster P. \& Röhl A. 1999. Median-joining networks for inferring intraspecific phylogenies. Molecular Biology and Evolution 16 (1): 37-48. http://dx.doi.org/10.1093/oxfordjournals.molbev. $\underline{\mathrm{a} 026036}$

Birdsall K., Zimmerman E., Teeter K. \& Gibson G. 2000. Genetic variation for the positioning of wing veins in Drosophila melanogaster. Evolution and Development 2: 16-24. http://dx.doi.org/10.1046/ j.1525-142x.2000.00034.x

Bookstein F.L. 1997. Landmark methods for forms without landmarks: morphometrics of group differences in outline shape. Medical Image Analysis 1 (3): 225-243. http://dx.doi.org/10.1016/S1361$\underline{8415(97) 85012-8}$

Brower A.V. 1994. Rapid morphological radiation and convergence among races of the butterfly Heliconius erato inferred from patterns of mitochondrial DNA evolution. Proceedings of the National Academy of Sciences 91 (14): 6491-6495. http://dx.doi.org/10.1073/pnas.91.14.6491

Chen H., Rangasamy M., Tan S.Y., Wang H. \& Siegfried B.D. 2010. Evaluation of five methods for total DNA extraction from Western Corn Rootworm Beetles. PLoS ONE 5: e11963. http://dx.doi.org/10.1371/ journal.pone.0011963

Dapporto L. 2010. Speciation in Mediterranean refugia and post-glacial expansion of Zerynthia polyxena (Lepidoptera, Papilionidae). Journal of Zoological Systematics and Evolutionary Research 48 (3): 229237. http://dx.doi.org/10.1111/j.1439-0469.2009.00550.x

Dušek J. \& Laska P. 1964. A contribution to distinguishing the European species of the subgenus Syrphus Fabricius (Diptera, Syrphidae) according to male genitalia and larvae. Acta Societatis Entomologicae Cechosloveniae 61 (1): 58-70.

Excoffier L. \& Lischer H. 2010. Arlequin Ver 3.5. 1.2 User Manual (2010) Computational and molecular population genetics lab (CMPG). Institute of Ecology and Evolution University of Bern, Bern.

Folmer O., Black M., Hoeh W., Lutz R. \& Vrijenhoek R. 1994. DNA primers for amplification of mitochondrial cytochrome c oxidase subunit I from diverse metazoan invertebrates. Molecular Marine Biology and Biotechnology 3 (5): 294-299.

Francuski Lj., Ludoški J., Vujić A. \& Milankov V. 2009. Wing geometric morphometric inferences on species delimitation and intraspecific divergent units in the Merodon ruficornis group (Diptera, Syrphidae) from the Balkan Peninsula. Zoological Science 26 (4): 301-308. http://dx.doi.org/10.2108/ zsj.26.301

Goloboff P. 1999. NONA (NO NAME) ver. 2. Published by the author, Tucumán, Argentina. 
AČANSKI J. et al., Species boundaries in the Merodon avidus complex

Hall T.A. 1999. BioEdit: a user-friendly biological sequence alignment editor and analysis program for Windows 95/98/. Nucleic Acids Symposium Series 41: 95-98.

Hasson E., Soto I.M., Carreira V.P., Corio C., Soto E.M. \& Betti M. 2009. Host plants, fitness and developmental instability in a guild of cactophilic species of the genus Drosophila. In: Eduardo B.S. (ed.) Ecotoxicology Research Developments: 89-109. Nova Science Publishers, New York.

Hewitt G.M. 1999. Post-glacial re-colonization of European biota. Biological Journal of the Linnean Society 68 (1-2): 87-112. http://dx.doi.org/10.1006/bijl.1999.0332

Hewitt G.M. 2001. Speciation, hybrid zones and phylogeography - or seeing genes in space and time. Molecular Ecology 10 (3): 537-549. http://dx.doi.org/10.1046/j.1365-294x.2001.01202.x

Hippa H. 1990. The genus Milesia Latreille (Diptera : Syrphuidae). Acta Zoologica Fennica 187: 1-226.

Hippa H. \& Ståhls G. 2005. Morphological characters of adult Syrphidae: descriptions and phylogenetic utility. Finnish Zoological and Botanical Publishing Board, Helsinki.

Hosken D.J. \& Stockley P. 2004. Sexual selection and genital evolution. Trends in Ecology \& Evolution 19 (2): 87-93. http://dx.doi.org/10.1016/j.tree.2003.11.012

House C.M., Lewis Z., Hodgson D.J., Wedell N., Sharma M.D., Hunt J. \& Hosken D.J. 2013. Sexual and natural selection both influence male genital evolution. PLOS ONE: 8 (5): e63807. http://dx.doi. org/10.1371/journal.pone.0063807

Hurkmans W. 1993. A monograph of Merodon (Diptera: Syrphidae). Part 1. Tijdschrift voor Entomologie 136: $147-234$.

Julius F. \& Kukla J.G. 1977. Pleistocene climates in Central Europe: at least 17 interglacials after the Olduvai event. Quaternary Research 7 (3): 363-371.

Klingenberg C.P. 2011. MORPHOJ: an integrated software package for geometric Morphometrics. v.2.0. [Computer software and manual]. Molecular Ecology Resources 11 (2): 353-357. http://dx.doi. org/10.1111/j.1755-0998.2010.02924.x

Konstantinov A.S., Korotyaev B.A. \& Volkovitsh M.G. 2009. Insect biodiversity in the Palearctic Region. In: Foottit R.G. \& Adler P.H. (eds) Insect Biodiversity: Science and Society: 107-162. WileyBlackwell, Oxford.

Marcos-García M.A., Vujić A. \& Mengual X. 2007. Revision of Iberian species of the genus Merodon (Diptera: Syrphidae). European Journal of Entomology 104 (3): 531-572. http://dx.doi.org/10.14411/ eje. 2007.073

Martinson D.G., Pisias N.G., Hays J.D., Imbrie J., Moore T.C. \& Shackleton N.J. 1987. Age, dating and orbital theory of the Ice Ages: development of a high resolution 0-300,000 year chronostratigraphy. Quaternary Research 27 (1): 1-29. http://dx.doi.org/10.1016/0033-5894(87)90046-9

McAlpine J. F. 1981. Morphology and terminology, adults. In: McAlpine J.F., Peterson B.V., Shewell G.E., Teskey H.J., Vockeroth J.R. \& Wood D.M. (eds) Manual of Nearctic Diptera: 9-63. Agriculture Canada, Ottawa.

Milankov V., Vujić A. \& Ludoski J. 2001. Genetic divergence among cryptic taxa of Merodon avidus (Rossi, 1790) (Diptera: Syrphidae). An International Journal of Dipterological Research 12 (1): 15-24.

Milankov V., Ludoški J., Ståhls G., Stamenković J. \& Vujić A. 2009. High molecular and phenotypic diversity in the Merodon avidus complex (Diptera, Syrphidae): cryptic speciation in a diverse insect taxon. Zoological Journal of the Linnean Society 155 (4): 819-833. http://dx.doi.org/10.1111/j.1096$\underline{3642.2008 .00462 . x}$ 
Mutanen M. \& Pretorius E. 2007. Subjective visual evaluation vs. traditional and geometric morphometrics in species delimitation: a comparison of moth genitalia. Systematic Entomology 32 (2): 371-386. http:// dx.doi.org/10.1111/j.1365-3113.2006.00372.x

Nedeljković Z., Ačanski J., Vujić A., Obreht D., Djan M., Ståhls G. \& Radenković S. 2013. Taxonomy of Chrysotoxum festivum Linnaeus, 1758 (Diptera: Syrphidae) - an integrative approach. Zoological Journal of the Linnean Society 169 (1): 84-102. http://dx.doi.org/10.1111/zoj.12052

Nedeljković Z., Ačanski J., Đan M., Obreht-Vidaković D., Ricarte A. \& Vujić A. 2015. An integrated approach to delimiting species borders in the genus Chrysotoxum Meigen, 1803 (Diptera: Syrphidae), with description of two new species. Contributions to Zoology 84 (4): 285-304. Available from http:// www.ctoz.nl/vol84/nr04/a02 [accessed 19 Sep. 2016]

Nicholls J.A., Preuss S., Hayward A., Melika G., Csóka G.Y., Nieves-Aldrey J., Askew R.R., Tavakoli M., Schönrogge K. \& Stone G.N. 2010. Concordant phylogeography and cryptic speciation in two Western Palaearctic oak gall parasitoid species complexes. Molecular Ecology 19 (3): 592-609. http:// dx.doi.org/10.1111/j.1365-294X.2009.04499.x

Nixon K.C. 2002. WinClada ver. 1.0000. Published by the author, Ithaca, NY, USA.

Perissoratis C. \& Conispoliatis N. 2003. The impacts of sea-level changes during latest Pleistocene and Holocene times on the morphology of the Ionian and Aegean seas (SE Alpine Europe). Marine Geology 196 (3): 145-156. http://dx.doi.org/10.1016/S0025-3227(03)00047-1

Popov G.V. 2010. Merodon alexandri spec. nov. - a new species of hoverfly (Diptera: Syrphidae) from the northern Black Sea Region. Studia Dipterologica 16: 133-151.

Popović D., Djan M., Šašić L., Šnjegota D., Obreht D. \& Vujic A. 2014. Usage of different molecular markers in delimitation of cryptic taxa in Merodon avidus species complex (Diptera: Syrphidae). Acta Zoologica Bulgararica 7: 33-38.

Popović D., Ačanski J., Djan M., Obreht D., Vujić A. \& Radenković S. 2015. Sibling species delimitation and nomenclature of the Merodon avidus complex (Diptera: Syrphidae). European Journal of Entomology 112 (4): 790-809. http://dx.doi.org/10.14411/eje.2015.100

Pröhl H., Ron S.R. \& Ryan M.J. 2010. Ecological and genetic divergence between two lineages of Middle American túngara frogs Physalaemus (= Engystomops) pustulosus. BMC Evolutionary Biology 10 (1): 146. http://dx.doi.org/10.1186/1471-2148-10-146

Radenković S., Vujić A., Ståhls G., Pérez-Bañón C., Rojo S., Petanidou T. \& Šimić S. 2011. Three new cryptic species of the genus Merodon Meigen (Diptera: Syrphidae) from the island of Lesvos (Greece). Zootaxa 2735: 35-56.

Ricarte-Sabater A., Nedeljković Z., Rotheray G.E., Lyszkowski R.M., Hancock E.G., Watt K., Hewitt S.M., Horsfield D. \& Wilkinson G. 2012. Syrphidae (Diptera) from the Greek island of Lesvos, with description of two new species. Zootaxa 3175: 1-23.

Rohlf F.J. 2006. TpsDig-Digitize landmarks and outlines. Ver. 2.05. [Computer software and manual]. Department of Ecology and Evolution, State University of New York at Stony Brook.

Rohlf F.J. \& Slice D.E. 1990. Extensions of the Procrustes method for the optimal superimposition of landmarks. Systematic Zoology 39 (1): 40-59. http://dx.doi.org/10.2307/2992207

Rotheray G.E. \& Gilbert F. 2011. The Natural History of Hoverflies. Forrest Text, Ceredigion.

Sheets H.D. 2012. IMP software series. [Computer software and manual]. Buffalo, New York: Canisius College. 
AČANSKI J. et al., Species boundaries in the Merodon avidus complex

Shikano T., Shimada Y., Herczeg G. \& Merilä J. 2010. History vs. habitat type: explaining the genetic structure of European nine-spined stickleback (Pungitius pungitius) populations. Molecular Ecology 19 (6): 1147-1161. http://dx.doi.org/10.1111/j.1365-294X.2010.04553.x

Soto I.M. 2012. Aedeagal divergence in sympatric populations of two sibling species of cactophilic Drosophila (Diptera, Drosophilidae): Evidence of character displacement? Neotropical Entomology 41 (3): 207-213. http://dx.doi.org/10.1007/s13744-012-0028-x

Soto I.M., Carreira V.P., Soto E.M., Márquez F., Lipko P. \& Hasson E. 2013. Rapid divergent evolution of male genitalia among populations of Drosophila buzzatii. Evolutionary Biology 40 (3): 395-407. http://dx.doi.org/10.1007/s11692-013-9223-x

Ståhls G., Vujić A., Perez-Banon C., Radenkovic S., Rojo S. \& Petanidou T. 2009. COI barcodes for identification of Merodon hoverflies (Diptera, Syrphidae) of Lesvos Island, Greece. Molecular Ecology Resources 9 (6): 1431-1438. http://dx.doi.org/10.1111/j.1755-0998.2009.02592.x

StatSoft Inc. STATISTICA (data analysis software system), version 12 2015. Available from www. statsoft.com [accessed 20 Feb. 2016]

Tamura K., Stecher G., Peterson D., Filipski A. \& Kumar S. 2013. MEGA6: Molecular Evolutionary Genetics Analysis version 6.0. Molecular Biology and Evolution 30: 2725-2729. http://dx.doi. org 1 10.1093/molbev/mst197

Thompson J.D., Higgins D.G. \& Gibson T.J. 1994. CLUSTAL W: improving the sensitivity of progressive multiple sequence alignment through sequence weighting, position-specific gap penalties and weigh matrix choice. Nucleic Acids Research 22 (22): 4673-4680. http://dx.doi.org/10.1093/nar/22.22.4673

Vujić A., Radenković S., Ståhls G., Ačanski J., Stefanović A., Veselić S., Andrić A. \& Hayat R. 2012. Systematics and taxonomy of the ruficornis group of genus Merodon Meigen (Diptera: Syrphidae). Systematic Entomology 37 (3): 578-602. http://dx.doi.org/10.1111/j.1365-3113.2012.00631.x

Vujić A., Radenković S., Likov L., Trifunov S. \& Nikolić T. 2013a. Three new species of the Merodon nigritarsis group (Diptera: Syrphidae) from the Middle East. Zootaxa 3640 (3): 442-464. http://dx.doi. org/10.11646/zootaxa.3640.3.7

Vujić A., Ståhls G., Ačanski J., Bartsch H., Bygebjerg R. \& Stefanović A. 2013b. Systematics of Pipizini and taxonomy of European Pipiza Fallén: molecular and morphological evidence (Diptera, Syrphidae). Zoologica Scripta 42 (3): 288-305. http://dx.doi.org/10.1111/zsc.12005

Vujić A., Radenković S., Ačanski J., Grković A., Taylor M., Şenol S.G. \& Hayat R. 2015. Revision of the species of the Merodon nanus group (Diptera: Syrphidae) including three new species. Zootaxa 4006 (3): 439-462. http://dx.doi.org/10.11646/zootaxa.4006.3.2

Vujić A., Perez-Banon C., Radenković S., Ståhls G., Rojo S., Petanidou T. \& Šimić S. 2007. Two new species of genus Merodon Meigen, 1803 (Syrphidae, Diptera) from the island of Lesvos (Greece), in the eastern Mediterranean. Annales de la Société Entomologique de France 43 (3): 319-326. http://dx.doi. org/10.1080/00379271.2007.10697527

Vujić A., Petanidou T., Tscheulin T., Cardoso P., Radenković S., Ståhls G., Baturan Ž., Mijatović G., Rojo S., Pérez-Bañón C., Devalez J., Andrić A., Jovičić S., Krašić D., Markov Z., Radišić D. \& Tataris G. 2016. Biogeographical patterns of the genus Merodon Meigen, 1803 (Diptera: Syrphidae) in islands of the eastern Mediterranean and adjacent mainland. Insect Conservation and Diversity. http://dx.doi. org/10.1111/icad.12156

Zelditch M.L., Swiderski D.L., Sheets H.D. \& Fink W.L. 2004. Geometric Morphometrics for Biologists: a Primer. Elsevier Academic Press, London. 
Zhu G., Liu G., Bu W. \& Lis J.A. 2013. Geographic distribution and niche divergence of two stinkbugs, Parastrachia japonensis and Parastrachia nagaensis. Journal of Insect Science 13 (102). http://dx.doi. org/10.1673/031.013.10201

Manuscript received: 4 January 2016

Manuscript accepted: 23 May 2016

Published on: 14 October 2016

Topic editor: Gavin Broad

Desk editor: Kristiaan Hoedemakers

Printed versions of all papers are also deposited in the libraries of the institutes that are members of the EJT consortium: Muséum national d'Histoire naturelle, Paris, France; Botanic Garden Meise, Belgium; Royal Museum for Central Africa, Tervuren, Belgium; Natural History Museum, London, United Kingdom; Royal Belgian Institute of Natural Sciences, Brussels, Belgium; Natural History Museum of Denmark, Copenhagen, Denmark; Naturalis Biodiversity Center, Leiden, the Netherlands. 
AČANSKI J. et al., Species boundaries in the Merodon avidus complex

Appendix 1. List of specimens used for wing geometric morphometric analysis, by geographical area and species.

\begin{tabular}{|c|c|c|c|c|c|}
\hline Species & Country & Population & $\lambda$ & q & $\sum$ \\
\hline \multirow{15}{*}{ M. avidus (Rossi, 1790) } & Bulgaria & Pirin Mts.* & 7 & 1 & 8 \\
\hline & Croatia & Umag* & 16 & 6 & 22 \\
\hline & \multirow{5}{*}{ Greece } & Drama* & 10 & 4 & 14 \\
\hline & & Lesvos island* & 20 & 1 & 21 \\
\hline & & Olympus Mts.* & 13 & 7 & 20 \\
\hline & & Peloponnesos* & 10 & 5 & 15 \\
\hline & & Pindos Mts.* & 11 & 9 & 20 \\
\hline & \multirow{2}{*}{ Italy } & Piemonte* & 15 & 1 & 16 \\
\hline & & Pisa* & 16 & 4 & 20 \\
\hline & Montenegro & Durmitor Mts. & 2 & 0 & 2 \\
\hline & \multirow{4}{*}{ Serbia } & Djerdap gorge & 1 & 2 & 3 \\
\hline & & Malinik Mts. ${ }^{*}$ & 7 & 2 & 9 \\
\hline & & Pčinja* & 29 & 3 & 32 \\
\hline & & Dubašnica Mts. & 1 & 0 & 1 \\
\hline & Turkey & Lake Baffa & 4 & 1 & 5 \\
\hline \multirow{3}{*}{ M. ibericus Vujić, 2015} & Morocco & Atlas Mts.* & 3 & 17 & 20 \\
\hline & \multirow[t]{2}{*}{ Spain } & Cádiz & 2 & 0 & 2 \\
\hline & & Sierra Nevada Mts.* & 15 & 0 & 15 \\
\hline \multirow{11}{*}{$\begin{array}{l}\text { M. moenium } \\
\text { Wiedemann in Meigen, } 1822\end{array}$} & \multirow{2}{*}{ Italy } & Zuclo* & 8 & 2 & 10 \\
\hline & & Castiglione Dei Pepoli & 6 & 0 & 6 \\
\hline & Montenegro & 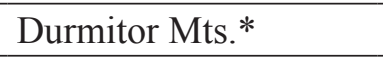 & 14 & 4 & 18 \\
\hline & \multirow{8}{*}{ Serbia } & Djerdap gorge* & 32 & 4 & 36 \\
\hline & & Dubašnica Mts.* & 16 & 2 & 18 \\
\hline & & Kopaonik Mts.* & 12 & 4 & 16 \\
\hline & & Stara Planina Mts.* & 18 & 5 & 23 \\
\hline & & Fruška Gora* & 17 & 0 & 17 \\
\hline & & Malinik Mts.* & 10 & 0 & 10 \\
\hline & & Tara Mts.* & 21 & 0 & 21 \\
\hline & & Vršačke Planine & 6 & 0 & 6 \\
\hline $\begin{array}{l}\text { M. megavidus } \\
\text { Vujić \& Radenković sp. nov. }\end{array}$ & Greece & Lesvos island* & 9 & 9 & 18 \\
\hline \multicolumn{3}{|l|}{ Total } & 351 & 93 & 444 \\
\hline
\end{tabular}


Appendix 2. List of specimens used for surstylus geometric morphometric analysis, by geographical area and species.

\begin{tabular}{lll}
\hline Species & Country & $\Sigma$ \\
\hline & Croatia & 7 \\
M. avidus (Rossi, 1790) & Greece & 9 \\
& Italy & 13 \\
& Serbia & 13 \\
& Turkey & 5 \\
\hline M. ibericus Vujić, 2015 & Morocco & 16 \\
\hline M. moenium Wiedemann in Meigen, 1822 & Spain & 17 \\
\hline M. megavidus Vujić \& Radenković sp. nov. & Montenegro & 8 \\
\hline Total & Serbia & 22 \\
\hline
\end{tabular}


Appendix 3. Neighbor-joining tree based on a 5' fragment of COI mtDNA sequences from the Merodon avidus complex. Bootstrap values (1000 replicates) are shown next to the branches.

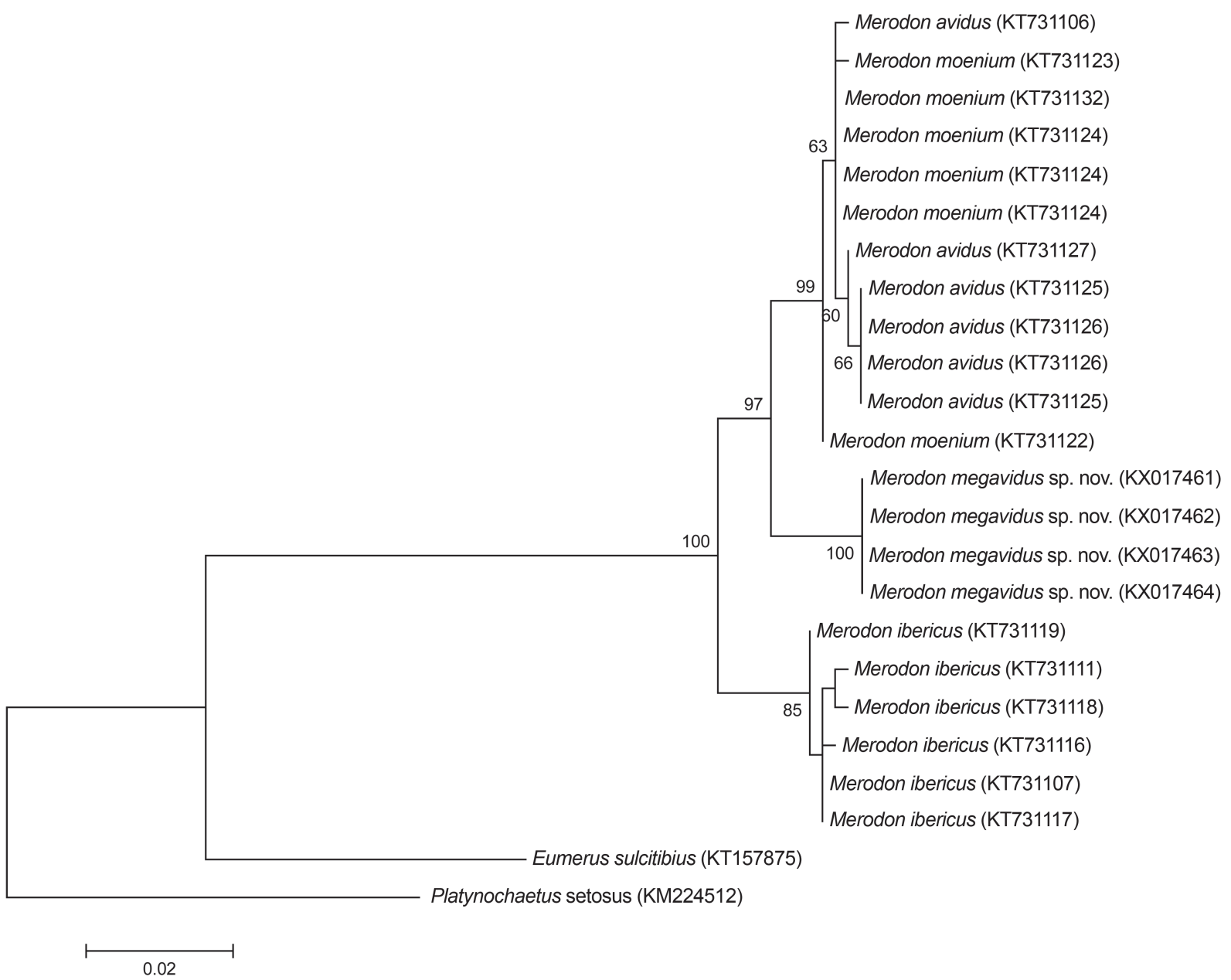

